Illinois State University

ISU ReD: Research and eData

Theses and Dissertations

3-17-2016

\title{
Hillman College Is A Different World From Where You Come From: A Thematic Analysis Of Relationships In A Different World
}

Natilie Williams

Illinois State University, nwillia@ilstu.edu

Follow this and additional works at: https://ir.library.illinoisstate.edu/etd

Part of the Communication Commons, and the Rhetoric Commons

\section{Recommended Citation}

Williams, Natilie, "Hillman College Is A Different World From Where You Come From: A Thematic Analysis Of Relationships In A Different World" (2016). Theses and Dissertations. 553.

https://ir.library.illinoisstate.edu/etd/553

This Thesis is brought to you for free and open access by ISU ReD: Research and eData. It has been accepted for inclusion in Theses and Dissertations by an authorized administrator of ISU ReD: Research and eData. For more information, please contact ISUReD@ilstu.edu. 


\title{
HILLMAN COLLEGE IS A DIFFERENT WORLD FROM WHERE YOU COME
} FROM: A THEMATIC ANALYSIS OF RELATIONSHIPS

IN A DIFFERENT WORLD

\author{
130 Pages \\ Natilie Yvonne Williams
}

This study focuses on the identity and relationships portrayed in the television series, A Different World. Although the popular series ended in 1993, this show continues to resonate with the African-American community. Specifically, Ron, D’Wayne, and Whitley are the primary characters of focus. Ron and D'Wayne maintain a brotherhood, while Whitley and D’Wayne maintain a romantic relationship. Both of these relationships include implicit expectations, illustrate varying levels of reciprocity, and provide identityshaping communicative feedback.

KEYWORDS: A Different World, Communication Theory of Identity, HBCU, Identity, Identity Negotiation Theory, Social Exchange Theory 
HILLMAN COLLEGE IS A DIFFERENT WORLD FROM WHERE YOU COME FROM: A THEMATIC ANALYSIS OF RELATIONSHIPS

IN A DIFFERENT WORLD

NATILIE YVONNE WILLIAMS

A Thesis Submitted in Partial

Fulfillment of the Requirements for the Degree of

MASTER OF SCIENCE

School of Communication

ILLINOIS STATE UNIVERSITY

2016 
(C) 2016 Natilie Yvonne Williams 
HILLMAN COLLEGE IS A DIFFERENT WORLD FROM WHERE YOU COME FROM:A THEMATIC ANALYSIS OF RELATIONSHIPS

IN A DIFFERENT WORLD

NATILIE YVONNE WILLIAMS

COMMITTEE MEMBERS:

Joseph Zompetti, Chair

Lauren Bratslavsky

John Baldwin

Pamela Hoff 


\section{ACKNOWLEDGMENTS}

This thesis has been a journey, but most importantly, it has been a passion project. I thank God for the peace that has made this such a low-stress venture, no matter how time consuming. I am beyond grateful to God for the wisdom and understanding that has gotten me to this very point in my life. Who would ever think that I would have my Master's at just 22 years old? I understand that I am nothing without God on my side, and for his love, I am very grateful.

Granny, I thank you for being my rock and always checking in on my thesis progress. Believe it or not, your level of anxiety sometimes became the motivation to work harder and produce this body of work.

Brian, "Thank you for being my friend, traveled down the road and back again." I am beyond blessed to have such a genuine friend that has made grad school seem like a breeze. I am forever thankful for your words of encouragement! No Limits No Boundaries.

To Nate, you have to know that your jokes, words of wisdom, and love have guided me through life's journey. Thank you for being the best dad that a girl could ask for.

To Mika and Crystal, where do I even begin? Thank you for the constant sisterhood that has made any life struggle seem like child's play. I count it all joy to call 
you all not only my friends, but my true sisters. From text messages to three-way calls of jokes, girl talk, and what it means to be a "Big Dog;" it's safe to say we are bonded for life, and nothing or anyone by any means will ever change that.

To Ariane, your friendship during graduate school made the transition that much easier. Thank you for being a true friend, at all times! Who knew that we would become life twins?

To Tony, thank you for always posing questions to make me think about my academic and professional future. Next up, it will be your time next. Remember that it is never too late!

To my Mom, though you may be absent physically, your spirit has helped me get through the last few years. I will never forget the lessons you taught me as a child. You made sure that I understood the importance of hard work and maintaining good grades. I always remember you stressing the importance of watching the company I keep. So I owe my thesis topic to you. You taught me the value and importance of relationships, as well as the power of connection. Everything that you instilled in me has made me into the woman I am today. So, I thank you, I love you, and I miss you! Heaven truly gained angel.

Dr. Zompetti, how far we have come! Your intelligence never ceases to amaze me. Thank you for providing me with structure and listening to me swoon over my love for this television show. You challenged me and made sure that I reached my academic potential. Thank you to Dr. Baldwin, Dr. Hoff, Dr. Bratslavsky for your guidance, never ending direction, and serving as members of my committee. 
To Jermaine Lamarr Cole and Kendrick Lamar Duckworth, your music has been the soundtrack to my collegiate years, both undergraduate and graduate school. From The Warm Up to Untitled Unmastered, I jammed the entire time when formulating this thesis.

N.Y.W 


\section{CONTENTS}

Page

ACKNOWLEDGMENTS $\quad$ i

CONTENTS iv

CHAPTER

I. INTRODUCTION 1

Statement of the Problem 2

$\begin{array}{ll}\text { Order of the Thesis } & 8\end{array}$

II. REVIEW OF RELATED LITERATURE 10

$\begin{array}{ll}\text { The African-American College Experience } & 10\end{array}$

Brief History \& Purpose of HBCUs 10

The Current State of African-American Experiences in College 12

$\begin{array}{ll}\mathrm{HBCU} \text { and PWI Experiences } & 12\end{array}$

Reasons for Choosing an HBCU 14

Representation of HBCU Culture in the Media 18

The Cosby Show 21

A Different World 23

$\begin{array}{ll}\text { Theoretical Background } & 28\end{array}$

Identity Negotiation Theory 28

Communication Theory of Identity 31

Identity and Relationships $\quad 36$

Social Exchange Theory $\quad 40$

$\begin{array}{ll}\text { Conclusion } & 41\end{array}$

III. METHODS 43 
Introduction $\quad 43$

Sample $\quad 44$

Method Justification $\quad 45$

Thematic Analysis $\quad 45$

$\begin{array}{ll}\text { Coding Procedure } & 47\end{array}$

Conclusion $\quad 48$

IV. ANALYSIS 48

Season 3 Episode 2 "The Heat is On" 50

Season 4 Episode 10 "Love Thy Neighbor" 53

Season 5 Episode 9 "To Tell The Truth" 55

Season 5 Episode 10 "Do You Take This Woman" 59

Season 5 Episode 13 'Just Another Four-Letter Word" 61

Season 5 Episode 25 "Save the Best for Last" 65

Season 6 Episode 3 "Interior Desecration or Sofa So Good" 67

Season 6 Episode 12 "Occupational Hazards" 71

Season 6 Episode 17 "When One Door Closes" 73

Season 6 Episode 18 "When One Door Closes" 77

Conclusion $\quad 81$

V. DISCUSSION 83

$\begin{array}{ll}\text { Simulacrum } & 82\end{array}$

$\begin{array}{ll}\text { Relational Themes } & 84\end{array}$

Pride, Frustration, and Selfishness $\quad 85$

Compromise and Understanding $\quad 85$

Theoretical Utility $\quad 86$

Colorism and Racial Identity $\quad 89$

Impact of Hillman College $\quad 91$

VI. LIMITATIONS AND FUTURE RESEARCH 93

$\begin{array}{ll}\text { Conclusion } & 97\end{array}$

$\begin{array}{ll}\text { REFERENCES } & 100\end{array}$

APPENDIX: TRANSCRIBED EPISODES 109 


\section{CHAPTER I}

\section{INTRODUCTION}

A Different World is a contradiction strictly based on its title. College is supposed to be a different world, but this show revolutionized an outsider's perception of a college campus. A Different World is a televised representation of real life, a simulacrum. As a simulacrum, television acts as a representation of society and has the ability to cultivate the view of society. Although the show aired from 1987-1993 and is more than 20 years old, the show represents trials, tribulations, and overall encounters of many AfricanAmerican students. The popular television series provided an insight to what happens at a historically Black college or university (HBCU). In this thesis, I will investigate the importance of relationships and the way in which relationships can assist with shaping identity while using $A$ Different World as the focus of this claim. The communication theory of identity, social exchange theory, and the identity negotiation theory will serve as the communication theories that will be applied toward the popular culture television series, A Different World. More specifically, I will analyze the relationships of the characters, Ron, D'Wayne, and Whitley. Ron and D'Wayne are friends and live together as roommates for a period of time. Whitley and D'Wayne have a romantic relationship during the series. As I dissect their relationships, I will also identify how their relationships with each other act as a catalyst to provide support and forms of constructive criticism to improve their identity 


\section{Statement of the Problem}

The show is based at Hillman College, a fictitious historically Black college/university (HBCU) that is described as being located in Virginia. The producers of the show capture the community-like environment that acts as a safe space for the students to grow within a positive atmosphere. The show tackles a wide range of issues, including: racism, rape, friendship quarrels, academic success, career options, romantic relationships, and religion. The episodes relate to then-current events that plagued the U.S., such as the Persian Gulf War and the HIV/AIDS epidemic. Hillman College signifies an academic institution that is like a site for the incubation of African-American students as they prepare themselves to be ready to change the world as they see fit.

Naturally, HBCUs can provide a community for African-American students. HBCUs pride themselves on providing a foundation for the cultural and racial identity of their students. It is no secret that HBCUs exist, and there is research investigating why African-American students choose $\mathrm{HBCUs}$ and the intangible attributes they gain from such a decision. The alumni lineage alone is a benefit that can be useful professionally, socially, and academically. A strong group of alumni can eventually turn into mentorship opportunities for incoming and younger college students. Alumni are able to pass on wisdom and knowledge to younger students with hopes to form a relationship that will encourage the student to make necessary self-improvements. Positive relationships are instrumental to the intrinsic growth of college students as they matriculate. College allows the opportunity to form beneficial relationships with people from different backgrounds and outlooks on life. College relationships with others - peers, staff, faculty, 
and mentors provide students with useful guidance and they help shape overall personal identity.

Unfortunately, research has not examined the relationships between the characters, D’Wayne Wayne, Ron Johnson, and Whitley Gilbert. These three characters represent friendships and romantic relationships that mature consistently as the characters go through college. College equipped these three characters with the tools to look at the world more broadly compared to when they first arrived to college. Whitely Gilbert, a wealthy African-American student, arrives to Hillman College as selfish and thinking herself to be better than others. According to Kelley (1995), "Throughout her years at Hillman, and because of her relationship with Dwayne who has much different values than she does, Whitley progresses” (p.183). D’Wayne Wayne is extremely intelligent and comes from a working class family in the inner-city of New York and is best friends and roommates with Ron Johnson, and also the back-and-forth love interest of Whitley Gilbert. Ron Johnson, the son of a car salesman, prides himself on being a ladies' man and does not take his academics as seriously as his peers. Ron, Whitley, and D'Wayne are the main characters of the cast, which peaks academic interest. These characters are worthy of study because they are able to be more accepting of people that may be different from them; additionally, these primary characters become more aware of the harsh ills of society, such as poverty, discrimination, and gender discrimination. College served as an incubator to prepare these three students for the "different world" they would soon enter after graduating college.

As the show progresses, these three characters face a multitude of life situations where they find their strength and comfort in the arms of their friendship or romantic 
relationships. Even when the characters attempt to do something foolish, they are forced to face reality through the correction of a relationship partner. Relationships are about an even level of give-and-take; the moment that a party of the relationship perceives an uneven level of give-and-take, issues and struggles will arise in the relationship. Once a partner in the relationship feels taken advantage of, the relationship can suffer and even reach the brink of dismantling. Social exchange theory represents the give-and-take nature of friendships and romantic relationships. For example, A Different World often utilizes humor and serious storylines to demonstrate the amicable nature or disagreements with the relationships of Ron, D'Wayne, and Whitley. These sorts of multi-dimensional relationships necessitate examination for greater understanding from an academic perspective.

As an African-American college student, I attended a Predominantly White Institution (PWI) for my undergraduate studies. There were times when I felt the reality of being the minority at my college institution. However, I felt a sense of community among the other African-American students that soon became my friends. We understood that we were the minorities in a numerical sense, and we became the support system for each other. That support system provided the assistance we needed to graduate within four years, study abroad, take advantage of internship opportunities, join lifelong organizations, and make friendships that would last beyond our collegiate years. The situations and friendships within $A$ Different World resemble those that I either personally encountered during my undergraduate studies or have seen others experience.

It was not until I studied abroad in Singapore that I finally understood my personal and academic obsession with A Different World. Studying abroad meant that I 
had to travel 9,000 miles away from home and my academic institution. I entered a "different world" with my support system that was only available through e-mail, phone calls, Skype, or FaceTime. The initial homesickness became heavy, and it was not until I received added encouragement from those that I love, that I then understood that everything would go well. While studying abroad, I would watch A Different World and would immediately feel a sense of calmness and peace. This show represented my life and undergraduate years, even though I did not attend an HBCU. Moreover, this show has the potential to reach those that do not identify as African-American, especially since the show portrayed situations to which college students of various racial backgrounds can relate. My academic experience forged a connection between academic success, positive relationships, and identity development, especially as a member of one of society's underrepresented groups. The series is emotionally and mentally stimulating, while also crafting the capacity for the viewer to be absorbed into the plot and story line of each episode.

After having a conversation with my graduate professor, I realized that $A$ Different World was comforting because I maintained a parasocial relationship with many of the characters, including D'Wayne, Ron, and Whitley. Schiappa, Allen, and Gregg (2007) define parasocial relationships as pseudo-interpersonal relationships with television characters. However, such relationships lack quality since the audience members cannot disclose any personal information to the television character. Instead, viewers feel a connection because the television character self-discloses to viewers, which allows viewers to mentally create a relationship between themselves and the characters. There are television shows that stay on air for many years, leading to 
parasocial that are deep-rooted and long-standing (Simpson, 1987). The writing staff is normally charged with being creative enough to create scripts that make characters have some ability to relate to their audience.

Writers intentionally attempt to create complex characters with whom audience members of different backgrounds and life experiences are able to form a relationship. Once multiple viewers are able to create a relationship with the television character, this creates loyalty to the television show and can possibly increase viewership, which directly relates to advertising sponsors and advertising dollars (Schiappa, Allen, \& Gregg, 2007). Speaking with a communication and media studies scholar solidified that I had indeed maintained a parasocial relationship with the characters of $A$ Different World (J. Zompetti, personal communication, 2015). Subsequently, my personal journey in "a different world" of Singapore, led me to become even closer to the show A Different World and my comfort zone within my own parasocial relationship, because the characters were on a similar journey in a world with which they had to grow familiar. This conversation assured me that I was not weird for feeling such a high-level connection to the show and the college environment that it displayed on television. Eyal and Cohen (2006) found that viewers who feel forms of loneliness are more likely to cultivate parasocial relationships with media characters as a coping mechanism. This finding provides a greater understanding of how $A$ Different World provided a way for me to cope with my homesickness during my international academic journey.

Ultimately, A Different World is a television show that serves as fundamental proof of the power of positive relationships and a strong support system. Through $A$ Different World, viewers are able to examine the dynamic of relationships between 
characters with differing personalities and upbringings. This is an adapted representation of life for many college students. Friendships and romantic relationships can provide practical criticism to help individuals improve their personal characteristics to become more socially conscious and self-determined. Relationships can also provide motivation to pursue academic and professional goals. A support system is the provider of additional emotional support from an outside source. College can be a challenging time, especially for first-year and first-generation college students. Positive relations, whether in the form of friendship or mentorship, can be the encouragement to succeed in college and build on personal development. Throughout the series, the relationships are developed and reflect cultural values of the African-American community. A Different World reveals that there is an interconnectedness of HBCUs, Black excellence, academic success, relational support, positive relationship formation, a sense of community, and complex identity development. Although some academic scholars, Allen (1992) specifically, proclaim the relation between the aforementioned characteristics, no one has completed an in-depth analysis while using $A$ Different World and the relationships as the foundation of their text.

Overall, A Different World is a unique television series that mirrors the HBCU experience for African American students. Jarrett Carter (2011) of The Huffington Post, exposes, "The value and social construct of the HBCU [sic] is but a subtext to a larger scope of showing personable young African-American” (par. 1). A Different World has cultural significance to the African-American community and is now engrained into the HBCU heritage. Journalists, those within the entertainment industry, and members of the African-American culture have acknowledged that $A$ Different World continues to 
influence the African-American community. The cultural significance of $A$ Different World is explains why this show is worthy of further study. Specifically, the intricate details of the show include the relationships between the characters, social support system of mentors, characters maturing in the safe space environment, social-economic status, colorism, sexism, and identity creation. All of these characteristics have a connection to communication theories. The depth of the televised relationships is full of communicative properties that merit research from a communication standpoint.

\section{Order of the Thesis}

First, this thesis will introduce the importance of investigating $A$ Different World. Specifically, it will examine the relationships started at an $\mathrm{HBCU}$ that persists through life events in an academic world. The relationships display a constant give-and-take nature, with one side often giving much more than the other. Nevertheless, each interaction provides constructive criticism for personal development and improvements to personal identity and racial identity. The research that has been completed investigates HBCUs, PWIs, and $A$ Different World, yet it stops short of investigating all of these topics together. The introduction will give reasoning for the need of this thesis. The purpose of this thesis is to take a popular culture television show and apply communication theories to the relationships between three of the main characters.

Next, the literature review will survey related studies that correlate to the foundation of the thesis, including relevant theoretical backgrounds with a focus on the communication theory of identity, identity negotiation theory, and social exchange theory. Additionally, the literature review will also include information pertaining to $A$ Different World and the HBCU experience. Similarly, the literature review will 
investigate studies on students that attend either an $\mathrm{HBCU}$ or a PWI, as well as the power of relationships to shape identity. The attention will focus on the lived experiences of African-American students and their constant mentioning of their sense of community at HBCUs. As we will learn, the sense of community will directly correlate to Ron, D’Wayne, and Whitley.

The third chapter discusses the methodology of the thesis. I will analyze video of the television series. I will then justify my use of specific episodes from various seasons. Character interactions that relate to the collective topics will be transcribed, critically analyzed, all while the related communication theories will be applied as a way of viewing the texts. I will use communication theories to further understand the relationships, then transcribed episodes will be analyzed to pinpoint the area in which the relationships between Ron, D'Wayne, and Whitley illustrate the specific communication theories. The textual analysis will examine the relationships using social exchange theory, communication theory of identity, and the identity negotiation theory as a lens.

Next, the following chapter - the analysis in chapter four - will present themes of communicative behavior exhibited by the main characters of $A$ Different World, integrated with information from scholarly theories and previous studies to provide an indepth textual analysis of the show. The relationships of Ron, D'Wayne, and Whitley will be critically analyzed as they correlate to the major themes and communication theories that are outlined in the text.

Lastly, the final chapter will conclude the entire thesis. The conclusion section will acknowledge limitations of this textual analysis and then present areas that are worthy of future research. 


\section{CHAPTER II}

\section{REVIEW OF RELATED LITERATURE}

This section will review the literature of the topics related to various areas covered within this text, including A Different World, The Cosby Show, the AfricanAmerican college experience, communication theory of identity, identity negotiation theory, and social exchange theory. African-American students can have varying experiences based on whether they attended a historically Black college or university (HBCU) or a predominately White institution (PWI). Each type of institution can provide an African-American student with life skills that are useful both academically and professionally. Both atmospheres allow African-American students to form relationships with other students and faculty members. These relationships may vary on the level in which they occur and affect the identity of the person in the relationship. Since relationships are about give-and-take, the social exchange theory takes a deeper look at the dynamic of the relationship between the two people.

\section{The African-American College Experience}

Brief history \& Purpose of HBCUs. According to Lemelle (2002), historically Black colleges and universities were created as academic institutions to provide an adequate education to the lineage of freed African slaves in the U.S. Cheney State University was founded in 1837 as the first HBCU. At one point, there were $150 \mathrm{HBCUs}$ in the U.S. (Lemelle, 2002). Currently, there are 103 HBCUs, and many of them are facing financial hardships, lacking the necessary resources to function and operate at a 
comparative rate of PWIs. The lack of alumni giving back to the university in the form of financial resources has severely impacted the endowment funds of HBCUs. HBCUs are often in the media for financial troubles and hazing with student organizations.

The media often control the stories of HBCUs, and they convey stories that traditionally sensationalize negative aspects of the institutions. Stroud (2014) suggests that HBCUs need to become less complacent and more proactive with "challenging the dominant discourse" and providing an alternate narrative (p. 15). In addition, HBCUs can make it a priority to publicize the accomplishments of the university, faculty, and students. An engagement with the prime-time media will give HBCUs some form of connection to the stories that are being told about their historic institutions.

HBCUs are still separate from PWIs in the conversation of higher education. Gasman and Bowman (2011) articulate that journalists write about leadership of postsecondary institutions, and HBCUs are treated is if they are not part of those academic institutions. The president of Central State University, Dr. Cynthia Jackson-Hammond, declares that HBCUs were never maintained to be exclusive to individual racial groups (Arnett, 2014); instead, they are present to serve those that remain underrepresented. In her words, these underrepresented groups include those that seek "to enrich their lives through academic experiences, and who had the desire to increase the economic, social, and moral fabric of their families" (p. 20). Van Camp, Barden, Ren Sloan, and Clarke (2009) believe that HBCUs have a tough time recruiting additional students that are academically prepared, especially when other academic institutions are vying for those same students to attend their respective universities. The plight of HBCUs focuses on the lack of alumni endowment, which then causes higher prices for students that desire to 
attend an HBCU. Some students at HBCUs often mention their less-than-favorable experiences with student services personnel. If students have consistently negative experiences with administration and staff, then those same students are less inclined to consider donating back to their alma mater after graduation.

The Current State of African-American Experiences in College. According to the 2010 U.S. Census (2012), in 2010 an estimated 18\% of African-Americans age 25 and over possessed the minimum of a bachelor's degree. In addition, in 2010 the U.S. Census reported that 2.9 million African-Americans were enrolled in college. As the number of African-Americans attending college increases, the amount of collegiate experiences increases as well. These college attendees have to decide if they prefer to attend an HBCU or a PWI, which relates to academic studies that focus on the factors that influence African-American students and their decision to attend an HBCU or PWI. Furthermore, these institutions and their students then have a greater chance of influencing both the personal and racial identity and the relationships of the AfricanAmerican students.

HBCU and PWI Experiences. Allen (1992) demonstrated that AfricanAmerican students who attended HBCUs reported higher levels of academic achievement compared to African-American students attending a PWI. He administered a study that investigated the relation of social involvement, the student outcomes of academic achievement, occupational aspirations, student's educational background, educational goals, demographic characteristics, and personal adjustment to college and the college environment. More than 2, 500 participants were African-American students at various universities - including 7 PWIs and 8 HBCUs—across the nation. The undergraduate 
student participants ranged from freshman to seniors. Allen (1993) studied the 953 responses from African-American students at the HBCUs and 1,578 from participants at the PWIs. Allen (1992) documented that the participants attending a PWI reported feeling less socially involved on their campus. Results also found a correlation between the amount of campus racial diversity and professional relationships with faculty. Students that have a positive relationship with faculty and feel a more unified relationship with other African-American students are again more likely to feel higher levels of social involvement on their respective college campus.

Overall, Allen (1992) came to the conclusion that African-American students reported more successful outcomes as students at an HBCU. Participants at PWIs acknowledged feeling alienated and receiving hostility from others. Heightened racial discrimination also caused the participants to have a lower sense of being properly integrated to campus. In contrast, African-American participants at HBCUs reported feeling connected with others and accepted on campus, while also receiving the necessary encouragement. Students mentioned receiving support from their academic, professional, personal, and social environment. Allen references human development and admits that HBCUs provide the basic necessities of ensuring that students feel safe and have a social association to their institution. HBCUs cultivate a safe social and psychological atmosphere for African-American students in comparison to PWIs.

Allen uses his research to prove the value of HBCUs and the impact of such institutions on African-American undergraduate students. Yet, this study purposely does not acknowledge how HBCUs assist students with finding their identity in a professional, academic, and cultural sense. Nevertheless, this thesis will do so with the primary 
characters of $A$ Different World. Although this study was conducted before the popularity of many of the applicable theories being utilized within this thesis, the author does not intend to dig deeper and investigate how the relationships formed at HBCUs shape the lives of students at the institutions.

Reasons for Choosing an HBCU. The cultural significance of HBCUs stimulates a response as to why African-American students may choose an HBCU instead of a PWI. Van Camp, Barden, Sloan, and Clark (2009) searched to find a sophisticated answer as to why African-American students at a private research-driven Mid-Atlantic region HBCU chose that particular university. A total of 176 African-American students participated in the study and completed 17 open-ended questions. Many of the participants acknowledged that they chose their HBCU for reasons in addition to those associated to race, including: economic status, location, the institution's academic reputation, and social opportunities.

Additionally, many of the students appreciated being around other AfricanAmerican students and desired to gain more insight into their African-American heritage and culture Many who chose an HBCU due to the focus on African-American culture also mentioned that they wanted to develop a greater insight into their own racial identity (Van Camp et al, 2009). Overall, the researchers found that HBCUs play a critical role in assisting African-American students to develop, explore, and cultivate their own racial identity. Approximately $70 \%$ of the participants were first-year college students. The study offered an explanation of why some African-American students choose their postsecondary institution.

Fries-Britt and Turner (2002) used the qualitative methods of interviews and 
focus groups to investigate the experiences of African-American students at both an HBCU and a PWI. The researchers focused on the support and hardships surrounding students' level of academic achievement. The first theme of accommodation focused on the support available to integrate students into campus, while the second theme dissected how students described the culture of their interactions on campus.

Participants attending a PWI reported feelings as if the campus programming mostly accommodated White students. These students lacked a sense of community at the institution due to the poor availability of Black students and faculty. Many of these students felt as if they were asked to be the voice for their entire racial group whenever related conversations took place; this differs from students attending an HBCU. Students at an HBCU reported that simple interactions with faculty and other students caused their personal confidence to increase (Fries-Britt \& Turner, 2002). One specific participant asserted that her HBCU was adamant about offering support and encouragement to attending students. A welcoming and inclusive environment can be the motivation for African-American students to find a sense of self and belonging while in college.

In contrast, students at a PWI did not use the specific term "community" to describe their campus or the overall environment, even if they did describe their academic program as having a family or community-like atmosphere (Fries-Britt \& Turner, 2002). In addition, many of those academic programs strategically attempt to retain and graduate an increased number of underrepresented groups at the university. The academic success of the students can remain affected by their level of satisfaction at their specific university. One participant reported that she was fearful of attending an HBCU, because she felt that a readily available, lively, and inclusive social environment 
would take away from her interest in academics. Many of the HBCU students admitted to having a live social scene at their university, and they utilized those opportunities to become more involved on campus and network with their fellow classmates. Students mentioned that HBCUs catered to the academic, cultural, and personal needs of students. It is common for the personal confidence of $\mathrm{HBCU}$ students to grow because they are given the opportunity to learn more about African-American heritage and lineage. HBCUs are known for teaching their students about African-American history and the value of HBCUs for African-American students.

Similarly, Holmes, Ebbers, Robinson, and Mugenda (2002) conducted research on successful ways to properly validate African-American students that attend a PWI. PWIs face the difficult task of creating environments that provides support to underrepresented groups, specifically African-American students. African-American students are exposed to lower retention rates if they are not able to adjust properly to the academic rigor and communicative atmosphere. This study revealed that there is a greater chance of an African-American prospective student enrolling at a PWI if they feel that they will be treated properly and add value to the PWI's campus.

In a comparative manner, Smith, Allen, and Danley (2007) conducted a study to explore PWIs and the experiences of 36 African-American male students attending the following PWIs: Harvard University, Michigan State University, University of California-Berkeley, University of Illinois, and the University of Michigan. The researchers examined reported instances of racially motivated microaggressions that affected the social and academic livelihood of the African-American male participants at PWIs. The researchers believe that constant micro aggressions cause racial battle fatigue, 
which makes the psychological effects worthy of study. Microaggressions can create subliminal or minor situations and behavior with negative subtle overtones with a lasting impact for those on the receiving end. For example, expecting an African-American student to speak for her or his entire race can represent a microaggression. When microaggressions summate over time, they can cause racial battle fatigue. Racial "battle fatigue" is defined as the "physiological and psychological strain exacted on racially marginalized groups and the amount of energy lost dedicated to coping with racial micro aggressions and racism" (p. 555). For African-American male students at elite PWIs, the negative racial climate can breed mental complexities that scar the student beyond what many can understand.

Focus groups and one-on-one interviews provided participants with a comfortable and safe environment to provide open and honest answers about their experiences with racial discrimination, including: their reaction to the discriminatory situation, whether the racial interaction affected their academic abilities, the benefits on the African-American community at their respective PWI, the current racial climate on their campus, and if they would refer other African-American students to their PWI (Smith, Allen, \& Danley, 2007). Collectively, the participants found it difficult to convey their identity in an environment that constantly marginalized them and misplaced their identity in a negative way. For instance, the students reported being treated as threatening bodies instead of as scholarly students, or they were viewed as incompetent instead of academically sound. They felt as if teachers and administrators at their respective universities acted as racial predators instead of protectors and educators. Yet, many of the students were able to move past such psychological ills by refusing to live up to the negative stereotypes that 
plagued their racial group on their college campus and on a national level. Their ability to endure racial battle fatigue and overcome the struggle of maintaining in an environment that is almost created to tarnish personal identity is a testament of their resiliency.

Smith, Allen, and Danley's (2007) study recognized that constant racial disparities and racial discrimination, whether subliminal or overt, can take a toll on the psychological well-being of an individual. The researchers provided a safe place to garner such purely honest explanations full of depth and critical responses. The participants detailed their responses to the "racial battle fatigue," but they stopped short of mentioning how such situations have shaped their identity as African-American men that are pursuing their collegiate degree at well-known and elite PWIs.

As we can see, previous research has examined the experiences of AfricanAmerican students that attend an HBCU or a PWI; however, these studies have not considered how popular culture television that represents African-Americans might impact college choices.

\section{Representation of HBCU Culture in the Media}

Television shows that strive to provide realistic portrayals of African-Americans, especially those with African-American writers passionate about African-American television, have a greater chance of inserting authentic African-American perspectives into popular culture (Hampton, 1989). This then provides an often-marginalized group with a voice that matters and asserts its culture into television with the hopes of wide exposure. Authentic depictions and representations allow people of any culture and racial background the opportunity to figuratively partake in experiences that are meaningful to African-American groups (Gray, 2000). Gray (2000) explains that multi-dimensional 
African-American television characters provide cultural variety and protect the characters from becoming token members that are charged with speaking for entire racial group. Furthermore, Gray (2000) documents that $A$ Different World depicts a diversified meaning behind the term "blackness."

The HBCU culture has been depicted in popular culture, both in television series and full-feature films. Each depiction served a different purpose and was perceived differently by its audience and academic scholars. For example, Black Entertainment Television (BET) debuted their reality television show, College Hill, in January 2004 (Smith, 2013). College Hill featured students at various HBCUs, including: Southern University. Langston University, Virginia State University, and the University of the Virgin Islands. The students lived together in one house and were filmed as they completed their daily activities. Within each season, the castmates worked together to complete some form of service within the surrounding community. For example, the students from season three taped at Virginia State University were filmed attending the funeral of Civil Rights legend Rosa Parks. Although the cast was filmed working together for a common goal, physical fights, disrespect, and negative stereotypes filled the season. The series showed two female housemates physically attacking each other, and one was hit in the face with the heel of a high-heeled shoe. College Hill quickly gained popularity, although negative stereotypes and depictions of African-Americans ran rampant. Many of the episodes were sexualized and explicit, as some students had even become characterized and type-casted. For example, season two of the show labeled the cast members as the following: "baller, rumpshaka, flirt, cheerleader, single mother, pretty boy, freak, and the good girl" (Parrot-Sheffer, 2008, p 211). College Hill ended in 
June 2009, not before presenting a negative portrayal of the rich history and legacy of HBCUs, given the constant exploitation within the show and negative representation of HBCUs.

Smith (2013) conducted a study to investigate a comparison of the portrayal of African-American women on College Hill versus the African-American men. Smith (2013) analyzed 141 scenes within 14 episodes of season three and 186 scenes within 16 episodes of season four. The results of the study revealed that the men had more positive portrayals than the female cast members (Smith, 2013). The public was presented with a one-sided perspective of the HBCU culture that focused on the social aspect, especially since the show took a keen interest in the social atmosphere.

School Daze is another artistic piece that focuses on the HBCU culture, yet using now legendary African-American actors with a musical twist throughout the movie. Spike Lee released School Daze in 1988 and focused on Greek life, colorism between lighter skin and darker skin African-Americans, as well as hair texture (Maslin, 1988). School Daze is based on a fictitious HBCU, Mission College, founded on 1883 with the sole purpose to "uplift the race" (Maslin, 1988, par. 10). School Daze was intentionally inserted into in the African-American community because it represents African-American Greek life culture and the social aspect of HBCU culture and tradition.

Drumline is another film that highlights HBCUs, more specifically, the popularity and the inner workings of the marching band. Media mogul Nick Cannon starred in the 2002 film. Bands are a major part of HBCU culture, and many of the African-American marching bands tour the country to showcase their musical abilities and unified skills. These marching bands showcase individuality by their high rhythm dance movements 
that are easily recognized by the African-American culture. Katzman (2009) unveiled greater details of the how HBCU marching bands maneuver on the football field in front of their audience:

First off, HBCU bands use a traditional high-step marching style, lifting the knees to 90-degree angles. This type of marching originated with schools in the Big Ten conference, primarily in the Midwest, where many band directors received their graduate and Ph.D. degrees. Also similar to Big Ten bands, HBCU bands emphasize turns by making right or left flanks with full 270-degree spins. However, HBCU bands take these traditional marching styles to a new level. Heads bob, arms swing, instruments get thrown in the air, and every movement accents the rhythm. (par. 4)

Drumline, much like similarly-themed television shows, portrays a fictitious HBCU and investigates a specific part of the HBCU culture and tradition, the life of the marching band. All of the films and television series listed above take the time to document and represent the HBCU culture. The aforementioned list does not include every film or television series focusing on an HBCU. Although there are other movies that highlight the HBCU culture, the amount of coverage of HBCUs does not come near to the amount of PWIs that are displayed in films and television series.

The Cosby Show. The Cosby Show ran on television in 1984 and ended in 1992, while its spinoff show, A Different World, started in 1987 and ended in 1993 (Matabane \& Merritt, 2014). Fuller (1992) documented that since its 1984 debut, every one of The Cosby Show's eight seasons became number one on the Nielsen charts for television, which gave the show political influence on primetime television. The Cosby Show 
portrayed a well-educated husband and wife, Clair and Cliff Huxtable, as parents of five children who made up an upper-middle class African-American family. Both parents were well-educated, with the father being a doctor and the mother a lawyer. The Huxtables were alumni of Hillman College, a fictitious historically Black college located in Virginia that was also the main academic institution featured in A Different World. Clair and Cliff Huxtable soon became a household name, as the "Huxtable" family became synonymous with a strong African-American family climbing the ladder of success, despite any challenges they may have faced as a family. African-American children were given the opportunity to witness a rare image, African-Americans thriving economically in one household. Bill Cosby was involved in multiple production-related aspects of The Cosby Show, including the writing and the types of specific props that were used in episode. Fuller (1992) refers to The Cosby Show as a "cultural artifact," especially since it portrayed a group of family members that were convincingly authentic to millions of homes on a weekly basis (p. 20). As any television show, The Cosby Show was subject to criticism that questioned the show's blackness, especially because the show highlighted a wealthy African-American family with professionally successful parents. (Griffin \& Hill, 1996). The blackness received continued criticism and questioning since there was a lack of attention given to social issues affecting the African-American community, including racism (Fuller, 1992). The criticism did not stop the show from becoming a staple in the African-American community and the television industry.

According to Matabane and Merritt (2014), The Cosby Show and A Different World identified educated African-Americans that achieved financial success during a 
time in which such images were not readily displayed in the media. The Cosby Show portrayed an upper-middle class African-American family with college-educated parents, while $A$ Different World documented African-American students pursuing an education at an HBCU. Over time, The Cosby Show became widely successful in the AfricanAmerican community and made a major impact on the type of academic and professional success that young African-Americans hoped to one day achieve. Matabane and Merritt (2014) describe the Cosby effect:

The Cosby Show inspired the creation of new films and television shows featuring student life at HBCUs, motivated existing Black sitcoms to incorporate visual and dialog references to HBCUs, and possibly may have a positive influence on students' decision to attend an HBCU. (p. 454)

The Cosby Show made it possible for the popularity of its spin-off, A Different World, while ensuring that social issues were at the forefront. The spin-off made sure that African-Americans were highlighted as educated, while remaining close-knit as they faced troubles common to college students.

A Different World. However, A Different World did not stop at simply portraying images of the African-American culture. Instead, the show garnered major support from its audience as it held on to its authentic depiction of social issues during the era in which the television show aired. The writers created storylines that still hold relevance today. Cosby brought in Dr. Alvin Poussaint, an African-American Harvard Medical School Dean and Psychiatrist, as a consultant for $A$ Different World. According to Gewertz (2005) of the Harvard Gazette, this duo agreed to place importance on education while also ridding their television project of simple "one-lines" while also avoiding "put-downs 
and negative humor" (par. 8). In 2014, Producer and director Debbie Allen revealed to Oprah Winfrey that $A$ Different World was the first television sitcom to discuss HIV/AIDS and the then-current AIDS epidemic. The episode that dealt with these issues caused advertisers to threaten withdrawal of their sponsorship if the episode continued or even physically showed a condom. Allen prides herself on the show remaining a pioneer on tackling tough social issues in a way that captivated an audience to continuously watch the show. Mark Harris of Entertainment Weekly (1991) described the show as "an ensemble comedy about black college life that's brightly acted, politically and socially attuned, idiosyncratic, and yes, even funny" (par. 4). Each character matured throughout each season and followed their goals as they figured out their life plans.

Many of the actors were not initially aware that the show would have such a positive impact and contribute to history in a significant way. In a September 2012 interview, Jasmine Guy, who played Whitley Gilbert, mentioned, "I felt that we were relevant for the times, but had no idea the show would last this long and that it would have that kind of impact on kids going to school" (Taylor, 2012, par. 3). The show lasted for six seasons, with episodes that are still applicable to current issues in contemporary society.

Surprisingly, A Different World did not start off as a series that was a believable representation of an authentic $\mathrm{HBCU}$ experience. The original writers attempted to mirror the success of The Cosby Show through telling similar innocent storytelling, which then lessened the authenticity of the HBCU experience. Season one suffered with low ratings, and a reassembly of main characters took place in order to gentrify the show and secure higher ratings. The show was deemed to be boring, and education was not at the forefront 
of the show in the first season (Pierson et. al, 2013). Debbie Allen was soon brought in to produce the show and create storylines that would prompt longevity for the show's legacy (Ramos, 2015). Allen brought her own knowledge of HBCU culture, since she had attended Howard University in Washington, D.C. (Stark \& Alexander, 1988). Allen provided a fresh perspective and a deeper understanding of how HBCUs operate compared to PWIs.

Specifically, Allen brought in a much-needed counter-narrative after she discovered that some of the show's Caucasian writers were lacking the ability to write scripts that were relatable to the African-American community (JET, 1992). This counter-narrative was so popular that JET magazine reported in its April 1992 publication that $A$ Different World was the most watched program by African-Americans for its 1990-1991 and 1991-1992 seasons (JET, 1992). Kovalchik (2015) documents that Allen took the A Different World writing team on field trips to Spelman and Morehouse Colleges, both HBCUs in Atlanta, Georgia, so they could have an accurate visual of the HBCU culture. The writers sat down with HBCU students and administrators to retrieve more detailed information from a variety of perspectives. This was one step that worked to improve the writing of the show to make it more appealing to a wider audience.

Unfortunately, Allen's counter-narrative of the first season brought much criticism from the network and advertisers. Since the show drew from realistic current events, the network became fearful and requested that writers alter the scripts to maintain a level of comfort for audience members (Kelley, 1995). Advertisers became so fearful that they actually began to remove their support for the show, thus causing $A$ Different World to lose much needed financial backing. Essentially, advertisers and their financial 
contributions are the primary way that television shows survive and stay on television networks. Nevertheless, A Different World continued to address many of the current issues that affected the African-American community and society as a whole.

For example, one of the episodes portrayed date rape, and advertisers and the network were concerned about backlash regarding this specific topic. However, Kelley (1995) posits that shelters for woman and high-school level sex education courses requested copies of this episode to use it as a teaching tool for women and students. According to Kelley (1995), A Different World was successful in its attempt to provide an alternate insight in to the African-American culture compared to what was normally displayed on television during that time period. While writing the show's scripts, Caucasian writers mentioned that they learned from their African-American writer counterparts (Kelley, 1995). A Different World was able to educate both its audience and writing staff on issues pertinent to African-American culture, including HBCUs.

HBCUs focus on providing a quality education to their students, while also educating them on the history of the African-American heritage and culture. Matabane and Merritt (2014) report that there is a greater likelihood that HBCU graduates will become involved in politics, religion, philanthropic endeavors, and study physical sciences compared to their counterparts of African-American students at predominantly White colleges. The Patterson Research Institute reported a 23\% increase in HBCU enrollment from 1984-94 (Nettles and Perna, 1997, p. 59). Hence, many of those connected to $A$ Different World like to attribute the enrollment increase to the positive images depicted within the television show. Over time, the show progresses and evolves as each of the characters mature. Gasman and Tudicio (2008) suggest: 
The early years of the sitcom focused primarily on the community developed on the Hillman College campus; the later years shifted focus to the issues surrounding those attending HBCUs: class, race, poverty, and sexuality. Of significance, the move allowed the show to switch from themes about how HBCUs affect students to how HBCUs can shape society. Both contexts create space for addressing the worth of HBCUs within American higher education. (p. 217).

Hillman College is a safe place for students and an environment that is suitable for personal, professional, and academic growth.

Nevertheless, there are also researchers that believe that $A$ Different World stereotypes African-American intellectualism, although the academic nature of Hillman College shines throughout the series. Parrott-Sheffer (2008) documents the characters' clean-cut appearance and "middle- to upper-middle" socioeconomic class in a negative manner, mentioning that $A$ Different World portrays a meticulous image as being associated with being an intellectual African-American (p. 213). Despite the overall legacy of the show, Parrott-Sheffer (2008) believes that the stereotypical images of collegiate African-Americans is discouraging to college-bound African-American students interested in attending an HBCU. Prospective students that do not identify with those stereotypical images of African-American college students may feel unwelcomed at an HBCU due to the physical presentation of the main characters.

Regardless of criticism, the longevity of the show's legacy and impact makes it a viable candidate for further study. A Different World has historical value to the AfricanAmerican community, as well as those that have a connection to historically Black 
colleges and universities. Audience members are given a chance to examine the culture of an HBCU and grasp an understanding of issues that college students may face. The show depicts the complex dynamic of intrinsic growth surrounded by an environment that is made conducive to the maturity of students. The story of each character highlights a larger piece of society. For example, Hillman College is made up of students like Whitley Gilbert, is an upper class members of the socioeconomic system, as well as Kimberly Reese. Throughout the show, Reese pays her own college tuition while working part time at the school eatery.

After the popularity of the show, producer Debbie Allen is accustomed to being bombarded with questions about the return of the television series. Allen admits that although the possibility of the show's revival has the public's attention, it would be an issue to mix the show's past writers to those that would be hired in present day (Obell, 2014). A Different World highlights the HBCU culture, which may just be a different world to some that may only attempt to experience such thing from watching a television screen.

\section{Theoretical Background}

Identity Negotiation Theory. During the course of the relationships shown on $A$ Different World, the characters negotiate their identity. Ting Toomey's (2005) identity negotiation theory includes ten core assumptions. The first assumption posits that collective membership within a group and individual personas are both created through communication that has a special meaning to those within the communication. Inclusion within groups that share similar cultural characteristics is much more plausible. The second assumption assumes that "identity security, inclusion, predictability, connection, 
and consistency" make up an identity negotiation spectrum (p. 218). Too much or not enough of those characteristics can cause issues within the negotiation of identity. Ting Toomey (2005) details that a lack of emotional security can cause a person to shy away from people with whom they do not have a personal relationship and that people feel uncomfortable around unknown individuals. The third assumption states that there is an increase in identity and emotional security in culturally homogenous environments and a decrease when one is in culturally heterogeneous environments. The fourth assumption proclaims that people are more likely to cherish inclusivity within groups when they are accepted without any hostility.

Ting Toomey's (2005) fifth assumption states that a person is more apt to predict the details of their interaction with people that share cultural characteristics. The predictability brings a sense of comfort and familiarity, while the absence of predictability breeds feelings of distrust. The sixth assumption states that people hope to develop platonically intimate relationships and can gain their own personal identity when close, trusting relationships are formed with those that may be part of a different culture. Within the seventh assumption, Ting Toomey (2005) writes that repetitive cultural traditions can foster identity familiarity, while unaccustomed changes in a cultural environment can weaken personal identity. The eighth assumption details that change within cultural and personal dimensions can dictate the assumed meaning of situations that shape identity. The ninth assumption proclaims that an effective process of negotiating an identity should contain education about other cultures. The information about outside cultures will assist with effectively communicating with members of differing culture groups. The tenth and final assumption asserts that adequate identity 
negotiation will breed feelings of positive self-images (Ting Toomey, 2005). Johnson (2002) posits that identity negotiation takes place with a purpose of adjusting personal perception and cultural conduct.

Academic and professional opportunities, including the accompanying relationships, can shape personal identity as it is being negotiated. Genovese (2015) observed the professional identity of sports reporters through qualitative methods such as interviews and observation sessions. Genovese found that African-American males and Caucasian women sports reporters have privilege when seeking to build a rapport while interviewing athletes, especially African-American athletes. However, the maintained masculinity of the sports industry does lessen the value of the identity of female sport reporters. These reporters have difficulty fulfilling the responsibility of negotiating racial identity and biological sex within respective professional organizations. Genovese reports that many of the participants admitted to struggling with combining their racial identity and biological sex while negotiating their identity as a news reporter. Women and minorities suffer the most when negotiating their multi-leveled identity, especially working in such a hyper-masculine industry.

Similar to the sports reporters in the work atmosphere, first-generation college (FGC) students find themselves negotiating and understanding their identity while experiencing college as a realm of their life. Orbe (2002) conducted qualitative interviews and focus groups with 79 first-generation college studies regarding their identity as such; out of the 79 students, 29 were African-American. Orbe (2002) found that many of his African-American participants took pride in their FGC status and understood that they have a responsibility to fulfill their academic goals, because they are 
leading an example for other members of their family. One African-American student stated that his family and surrounding community view him as a "liaison" to successfully completing college (p. 141). This student shared a story of visiting home and having community members being excited to communicate with him regarding his college experience, because it is not an experience that those community members have successfully completed for themselves (Orbe, 2002). Attending college shapes these students' identity because some students feel the pressure of embodying studious characteristics as they progress towards college graduation with the objective make their family proud. Many of the $A$ Different World characters dealt with their academic identity; too often they found themselves struggling to make their family proud through collegiate success. Not all of the three characters of focus in A Different World are FGC students, but they are new to college and must negotiate their identity in the context of the new surroundings and their introduction to their college experience.

Communication Theory of Identity. Michael Hecht and his fellow researchers created the communication theory of identity after they found an intersection between identity and communication, especially within inter and intra-cultural communication (Hecht, 1993). Communication cannot be dissected from identity, since socialized behaviors are displayed through verbal communication (Jung \& Hecht, 2004); therefore, multiple frames of identity include the personal, enactment, relationship, and communal layers. Each frame plays an integral role in the communication theory of identity.

The personal identity frame is made up of characteristics that are viewed through self-concepts (Jung \& Hecht, 2004). Next, the enacted identity layer focuses on the manner in which an individual expresses their personal characteristics. Jung and Hecht 
(2004) believe that identities are first enacted then exchanged in verbal communication. However, those enactments are not just associates of identity, instead, those enactments are actual identity and remain synonymous.

The third frame, described as relational identity, contains four subparts. Jung and Hecht (2004) document that an individual can mold their identity based on their intrinsic evaluation of how they believe others view them. The authors then state that an individual creates their identity in regard to their relationships with other people. Since an individual may have multiple relationships spread out among multiple people, the individual then has multiple identities to satisfy each relationship. For example, a person can be both a doctor in their professional life and also act as a sibling to their brother or sister in their personal life. The final subpart acknowledges that a joint relationship among two people can breed its own collective identity. The fourth and final frame is the communal identity frame. This frame considers identity in the midst of a large group, such as society. When finalizing an identity in the fourth frame, conflict can take place within relationships.

Hecht et al. (2002) apply the communication theory of identity to the television show Northern Exposure and showcase the utility of this theory. The research first focused on the communal identity of Jewish Americans, then deciphered how the communal identity permeated the individual, interactional, and relations ranks of identity (Hecht et al., 2002). Northern Exposure is a syndicated television show that has a main focus on the identity of Jewish Americans. The researchers analyzed six episodes of Northern Exposure and realized that the Jewish American personality was present in the reviewed episodes, which produced a connection between the communal and personal 
frame (Hecht et al., 2002). The study was focused on identity and a popular television show, which is a great indication of applying this theory to A Different World and the identity of its characters.

In a different study, Carron (2013) applies the communication theory of identity to identities that are displayed on the social networking site Twitter. Fifteen participants participated in qualitative interviews. During the interviews, participants discussed their personal Twitter accounts and profiles, specifically tweets that were sent from associates and their interaction with other users on Twitter. Participants admitted to using Twitter as a way to stay informed about current events and also to inform others simultaneously. Some Twitter users mentioned that they use Twitter simply to tweet their personal thoughts.

Overall, participants used Twitter to shape their identity at all four levels of the communication theory of identity. At the personal level, some participants revealed that they used Twitter as a platform to reveal their individualistic identity. Some even complained that negative feedback from their personal tweets meant that maybe their audience misperceived their tweets, in return, misinterpreting their personal identity. Within the enactment frame, participants attempt to conjure tweets that were accurate representations of themselves with the hopes that their audience will gain a better understanding of the user's identity. The relationship frame is identified through participants' interaction with other Twitter users. Some participants mentioned that they created relationships with other Twitter users on Twitter. The interactions between the users reflect the identity of users on both ends (Carron, 2013).

Lastly, the communal frame focuses on the collective nature of identity. As a 
whole, Twitter allows for groups to section off and express themselves collectively and share ideas. Carron (2013) describes a Twitter hashtag as the perfect example of the communal identity. Once a Twitter user uses a specific hashtag in a tweet, they become connected and a representative of the identity of the related hashtag. Just by utilizing Twitter, users are already part of a communal identity, whether they tweet with a hashtag or not. Carron's (2013) study is a great indication of the various levels of identity and the way in which social media, more specifically; Twitter users aligns with the communication theory of identity.

Carron's (2013) study takes an in-depth look at Twitter users and how they shape their identity on the social networking site. Surprisingly, Carron does not mention "Black Twitter" at all in her scholarly work. "Black Twitter" is a collective body of savvy, comedic, empowered, sarcastic, and aware group of African-Americans that pride themselves on speaking the truth on Twitter. This specific group of Twitter users has grown numerically and takes pride in their name and abilities to immediately cause attention to any issue that they band together to discuss on the public forum. In 2013, the Pew Research Center documented that $27 \%$ of all African-American Internet users are members of Twitter, while $30 \%$ of overall Twitter users are African-American (Brenner \& Smith, 2013). However, this is a clear increase from the 2010 Pew Research Center documentation that $13 \%$ of Twitter users were African-American (Smith \& Raine, 2010). McDonald (2014) describes knowledge as the only admission charge to join Black Twitter. Furthermore, "if you have spent time in the black culture, whether a historically black college or university or in the university or in the company of friends or family, you will probably understand the references on Black Twitter" (McDonald, par. 5). 
Twitter allows for open discussion on topics that are pertinent to its users. It would have been interesting to see Carron (2013) search for Twitter discussions that are founded upon A Different World. The next step would have included searching for common themes among tweets that pinpointed $A$ Different World as the main focus; however, that leaves space for future research with social media and popular older television series.

Black Twitter has been the driving force behind Debbie Allen and cast members being bombarded with messages to bring $A$ Different World back to television. In a 2014 interview with Oprah, Debbie Allen admitted that she received repeated communication on Twitter and other social networking sites to bring the $A$ Different World back to television. Black Twitter is a collective group that has the power to make changes, provide feedback to large corporations, and bring attention to any issues that they believe has value. Black Twitter takes conversations that were once isolated within hair salons, barbershops, HBCUs, and churches that are all targeted towards African-Americans, and makes them available to the world (Guo, 2015). The entire $A$ Different World series is now available on Netflix which allows the show to spark much conversation among Black Twitter users (Ramos, 2015). It is common for users of Black Twitter to reminisce on African-American television shows that have had an influence on the AfricanAmerican culture.

Alternatively, Nuru (2014) examines the complex identity of transgender individuals with the communication theory of identity as the theoretical foundation. Nuru (2014) transcribed videos that transgendered people posted onto ItGetsBetter.com, which is a website that serves as a safe place and open forum for transgendered people. A total of 37 videos were transcribed precisely with a focus on videos that discussed transgender 
people and their decision to have surgery to reassign their biological sex (Nuru, 2014). Identity gaps were the main focus as Nuru studied the transcribed videos for recurring themes; the identity gaps are defined as difficulty and conflict with identity negotiating across the following four identity layers: personal-enacted, closeted enactment, and personal-relational identity. Nuru came to the conclusion that transgender individuals do not have one solid identity that they maintain on just one level of the communication theory of identity. Instead, their identity resides on multiple levels of the theoretical framework simultaneously.

Nuru's (2014) study provides a better understanding of the identity of transgender individuals. The communication theory of identity allows for the complexity of identity to not be forced into only one level of the framework. Instead, Hecht created the theory to allow for identity to be recognized and placed across a spectrum of identity. In the context of $A$ Different World, the three characters constantly seek understanding of the multiple frames of their identity as the frames are explained by the communication theory of identity. The television offers a glance into characters' lives through their relationships with others and their pursuit to better understand themselves.

Identity and Relationships. Identity plays a major role in how people choose to communicate with others. Social and romantic relationships, with a communicative focus, can play a role in the intrinsic growth of an individual. These types of relationships can be the inspiration to follow professional and overall life goals. Feeney and Collins (2015) find that relationships can provide emotional encouragement and assist in dissolving problems that may arise. Those that provide support are available during the times of hardship and happiness. The authors believe that a supporter should be able to 
uphold the confidence of another person, which will then grant feelings of security and diminish emotional discomfort. As such, "those who are able to effectively restore an attached person's felt security when needed—by providing emotional comfort and facilitating problem resolution" (Feeney \& Collins, 2015, p. 116).

When the support is presented, Feeney and Collins (2015) reference this as the "Source of Strength (SOS) support" (p. 116). This concept mainly relates to the ability for one to successfully maneuver through tough times, while also thriving. The first step to thriving is the beginning of the fortification process. Fortification takes place when a person of support assists a friend or relationship to partner see their own personal strength and positive abilities that may have otherwise gone overlooked or underestimated (Feeney \& Collins, 2105). The strength and positive abilities will be motivation to obtain the necessary skills to be productive and self-sufficient.

The next step of SOS includes assisting in the reconstruction process after the fortification process is complete. Encouragement of those in close connection is provided to put the positive strengths and abilities into motion, along with people being able to acknowledge opposing forces that may arise. The pursuit of goals should remain as the main focus instead of harping on negativity. However, assisting in reframing/redefining the adversity is instrumental in the success of the reconstruction process (Feeney \& Collins, 2015). The adversity is reevaluated into decreasing the perceived visibility of a threat. According to Feeney and Collins (2015), the adversity should be perceived, by the person needing the motivation, as insignificant—something that is no longer an impossible hurdle — while once again promoting a thriving intrinsic change within the individual. A positive mindset will transform a hurdle into a step as part of a process of 
growth and new beginnings. For example, discontinuing a childhood friendship turned tumultuous can be scary and bring about many fears. However, transforming this adversity will allow the individual to see it as an incentive to maintain and cultivate other friendships that add value.

Comparatively, Feeney and Collins (2015) present the notion of Relational Catalyst $(R C)$ support that stress promotion of thriving through life opportunities. The first step within this theme includes nurturing a desire to create and/or seize life opportunities for growth. Those within the relationship, either platonic or romantic, encourage their relationship partner to follow after their own goals and dreams in a tenacious manner, no matter the past, present, or future circumstances. Feeney and Collins (2015) detail their explanation of life opportunities and the role of relational catalyst support:

This includes expressing enthusiasm for life opportunities; validating a close other's goals, dreams, and aspirations (both big and small); encouraging a close other to challenge or extend himself/herself to grow as an individual (e.g., leave one's comfort zone to try challenging as well as familiar activities); communicating the potential benefits of creating/ pursuing life opportunities; and providing encouragement to embrace even small opportunities that may be stepping stones to bigger ones. Because opportunities are not always readily available, the encouragement to take initiative in creating one's own opportunities is an important part of motivating the pursuit of life opportunities. (p. 119) The Relational Catalyst is valid through the provision of perceptual assistance in the viewing of life opportunities. Primarily, relationship partners push their other person to 
visualize the optimistic nature of life instead of focusing on the difficulty of opportunities that may soon arise (Feeney \& Collins, 2015). For example, a person may encourage a friend to accept their dream job, even if the friend is initially nervous about their ability to fulfill the duties of the professional position.

Finally, the third function of the Relational Catalyst includes the facilitation of preparation for engagement in life opportunities through the exposure and expansion of cultivating the necessary abilities that are essential to fulfilling the duties of the "life opportunities" mentioned above (Feeney \& Collins, 2015, p. 7). This function serves the purpose of allowing the person to become more acquainted with their personal selves. However, Feeney and Collins (2015) recognize that support does not mean that struggles will not be present; yet, the support increases the likelihood that one will be able to surpass the struggles and pursue their goals (Feeney \& Collins, 2015). Supportive relationships can play a major role in the personal growth of another person who is able to put the encouragement to use.

Feeney and Collins (2015) explore the importance of relationships in a very broad sense. Their research examines identity and relationships, and allows for future research to focus on television shows that depict the importance of relationships and identity that is gained along the way. Future research can also narrow the scope to include relationships within the African-American community, more specifically at academic institutions. Relationships that are platonic and romantic are constantly shown throughout A Different World. These relationships provide consistent constructive criticism to partners and normally lead the story line that ends with "moral of the story" type of plot 
Social Exchange Theory. This thesis is focused on relationships within $A$ Different World. In its simplest form, social exchange theory acknowledges reciprocity within relationships. According to Xanthopoulou, Demerouti, and Schaufeli (2009), social exchange theory recognizes that people in relationships will eventually develop a "trusting, loyal, and mutual commitment" (p. 877). The individuals within the relationship may have both implicit and explicit expectations of the other person in the relationship. For example, college roommates may have explicit negotiations that each roommate will pay a portion of the rent. However, issues can arise in relationships with implied expectations, especially when these expectations turn into mental assumptions that have yet to be fairly negotiated. One-sided implied expectations can cause unmet goals in a relationship. For example, in the case of two best friends, one friend may always be a support system for the other friend and the support may not be reciprocated. If the parameters of social support have yet to be explicitly stated, there is an increased possibility that there will be an uneven level of exchange within the hypothetical friendship. In any form of relationship, people want to feel that they are receiving a comparable amount of whatever they themselves are putting in to their relationship. Social support and social exchange theory relate to this study because the three characters provide each other with a constant flow of social support through give-and-take relationships. This social support becomes a necessity as the characters academically matriculate and increase their personal growth through live experiences. 


\section{Conclusion}

College is a great time to develop personal characteristics that will be empowering for life beyond the academic institution. Specifically, HBCUs have garnered the reputation of not only being an institution of higher learning, but also a place to promote personal racial development and enhance the overall well-being of students. As shown in the research above, relationships are often labeled as the foundation of social and academic success at HBCUs. Students and their willingness to help their fellow schoolmates, no matter the tough times in the relationship, appear throughout $A$ Different World. This becomes a theme engrained into the overarching messages of the show. This review of literature indicates that little research has directly explored $A$ Different World. The interpersonal relationships depicted on A Different World will be better explained with the use of the interpersonal communication theories. As a result, my rhetorical thematic textual analysis is necessary to understand relationships in A Different World. This thesis seeks to answer a variety of questions regarding the relationships and identities of key characters within A Different World.

According to the communication theory of identity, how does the relationship between Ron, D'Wayne, and Whitley penetrate each of their identities, both collectively and individually? With the identity negotiation theory in mind, how does the Hillman College academic atmosphere influence the identity of Ron, D'Wayne, and Whitley? Relationships are about balance, so how does social exchange theory help to explain Ron, D'Wayne, and Whitley as they navigate their college life and personal development and growth? This thesis will use the aforementioned communication theories as a lens to 
investigate the relationships portrayed in A Different World. The main focus will analyze the relationships between Ron, D'Wayne, and Whitley with reference to the constant back-and-forth nature of their friendly and romantic relationships. 


\section{CHAPTER III}

\section{METHODS}

\section{Introduction}

This chapter will outline my methods for a close thematic textual analysis of $A$ Different World. First, I will provide information about the sample, which will include 10 episodes of $A$ Different World. I will justify my rationale for selecting specific episodes spanning across multiple seasons. Next, I will provide the context of a thematic textual analysis and supply examples of this method from previous research. Additionally, this chapter will contain detailed information about my coding and transcribing procedure and present my process of using the communication theories as a lens to analyze the relationships between the characters.

\section{Sample}

A Different World was chosen as the foundation of this thesis because it has become a fixture in popular culture that is important to the African-American community. In 1988, the Associated Press published an article in The New York Times about the popularity of $A$ Different World. In the 1987-88 television season, $A$ Different World was viewed in more than 22 million homes and was rated as the number two top regularly scheduled prime-time television show.

My analysis is focused on $A$ Different World, using 10 episodes. The episodes have been used for a rhetorical textual analysis that spans across seasons three through 
six. Episode summaries were used as a guide to pick the specific episodes that correlate with a relationship-focused plot. The episodes, although spanning across various seasons, were chosen for multiple reasons. As discussed earlier in this text, A Different World went through organizational changes after the first season. Writers were fired, while new writers were brought in, and Debbie Allen was hired as a producer of the show. Allen ensured that writers had a genuine understanding of HBCUs and how they operate, especially with respect to the services that these institutions offer to their students (Ramos, 2015). Allen made sure that each character was complex in nature, possessing a multi-layered personality and interesting family life. The popular television show ended after the sixth season was aired on NBC. By the third season, the characters had a better understanding of their collegiate environment and faced more mature situations. Similarly, by the sixth and final season, Ron, D'Wayne, and Whitley had their relationship issues that shaped their identity; these issues were in preparation for D'Wayne and Whitley to eventually journey off to their version of "a different world" after D'Wayne accepted a professional position in Tokyo and learned that he and his wife Whitley were expecting their first child. The issues between Ron and D'Wayne were also in preparation for Ron to have to part with his college best friend and renegotiate his identity in light of these changes. The 10 episodes that were used as a subject of focus emphasize any combination of the relationships of Ron, D'Wayne, and Whitley. Although other episodes in the collection may focus on relationships between background characters, this thesis will focus on the relationships between the three aforementioned characters, as well as the negotiated identity of these three characters. 


\section{Method Justification}

I will be transcribing the relationship-focused portions of the episodes of $A$ Different World. These episodes are indicative of the following communication theories and overarching topics, including: social exchange theory, communication theory of identity, identity negotiation theory, and the focus of identity and relationships. This methodology will provide clear evidence of the relationship between the characters and will also use scholarly theories as an application to gain better insight of the creative material featured in A Different World.

\section{Thematic Analysis}

Thematic analyses can be utilized to distinguish specific themes within a text in order to pursue further investigation of those themes (Guest, MacQueen, \& Namey, 2011). Instead of calculating the appearance of specific words, thematic analyses concentrate on both implied and obvious themes within an object of study (Guest, MacQueen, \& Namey, 2011). Joffe and Yardley (2004) documented that a thematic analysis can combine the number of thematic occurrences and the overall meaning of the themes in relations to the text in question. A thematic analysis not only distinguishes reoccurring themes, but it seeks to understand those same themes (Joffe, 2012). A thematic analysis searches for clarity and meaning within the text.

Fürsich (2009) used a textual analysis to study producer's objectives when creating media content in comparison to the interpretation of viewers of the same work. According to Fürsich (2009), a textual analysis is qualitative and examines the overall "ideological and cultural assumptions of the text" (p. 240). A textual analysis recognizes the author's creative text, but allows the audience to create their own interpretation, 
whether it differs from the original and desired meaning of the producer, while a thematic analysis recognizes themes and then begins a journey of investigation.

An inductive thematic analysis begins with specific encounters in order to create generalizations. Pehlke, Hennon, Radina, and Kuvalanka (2009) studied 12 comedic television series across six major networks with an inductive thematic analysis method while using fatherhood as the thematic foundation. These researchers watched the shows and took notes while observing the conversations between characters. Next, the researchers began to arrange the moments that the topic of fatherhood was mentioned. The third stage included connecting the variety of themes in relationship to fatherhood. The authors discovered five sub-themes connected to the portrayal of fatherhood in the television series, including: fathers being financial providers in the household, fathers completing household chores, fathers interacting with their children, fathers interacting with the mother of their children, and fathers interacting with individuals outside of their family life. The researchers applied these themes to the fatherhood portrayal based on the race and socioeconomic status of the fathers in the television show. Surprisingly, Pehlke et al. (2009) found that African-American and Latino fathers were portrayed more positively compared to White fathers.

However, the authors documented that an inductive thematic analysis has a limitation that would allow a researcher to insert their own biases into the thematic coding sessions (Pehlke et al., 2009). This limitation is a realistic possibility for scholars that utilize this method in their academic and professional research. In this thesis, I cannot eliminate bias, but instead I can be upfront about my biases and keep the analysis centered on relationship themes. As previously discussed, I am passionate about this television show, 
and I also admire the dynamic of the relationships between Ron, D'Wayne, and Whitley, while also viewing those relationships in an overall favorable manner. My other biases would include my status as an African-American woman that attended a PWI for graduate and undergraduate studies.

\section{Coding Procedure}

I watched $A$ Different World looking for specific relationship-focused themes. Once specific themes appeared, I transcribed those specific scenes within the series' episodes. Themes relating to the relationships include: conflict, confrontation, constructive criticism, social support, and encouragement. With the communication theory of identity, social exchange theory, and the identity negotiation theory in mind, I watched the episodes and look for keys words and themes to indicate the nature of the relationships. Next, I completed a close textual analysis of the transcribed interactions between Ron, D'Wayne, and Whitley. The overarching themes were evident after I watched the specific episodes. The inductive approach will be the main approach to closely watching A Different World. Furthermore, with the aforementioned communication theories as a guide, I interrogated the transcribed text to provide a greater understanding of the relationships and the characters' identity.

Even before the scenarios were transcribed, the theories were be used as a lens to interpret the meaning of the scenarios. I paid attention to the characters' interactions watching for instances when they communicate, verbally or non-verbally, their overall relationship and their identity in context of their relationships. My areas of focus included the following: 
(a) According to the communication theory of identity, how do the relationships between Ron, D’Wayne, and Whitley penetrate each of their identities, both collectively and individually?

(b) With the identity negotiation theory in mind, how does the Hillman College academic atmosphere influence the 2identity of Ron, D'Wayne, and Whitley?

(c) Relationships are about balance, so how does social exchange theory help to explain Ron, D’Wayne, and Whitley as they navigate their college life and personal development and growth?

\section{Conclusion}

This chapter outlines the thematic analysis that I used to investigate the transcribed relationship-focused interactions of the characters of $A$ Different World. I used specific communication theories as a lens to better understand the relationships of Ron, D’Wayne, and Whitley. Each of the communication theories provided a framework for my interpretation of the scenarios. The next chapter will present the themes from the episodes that focus on the relationships of the characters. 


\title{
CHAPTER IV
}

\begin{abstract}
ANALYSIS
I watched 10 episodes of $A$ Different World that had a focus on the relationships - of D'Wayne and Ron, as well as Whitley and D'Wayne. I analyzed these episodes, only coding specific relationship-related interactions between these characters. These relationship-related interactions focus on conflict, identity, as well as social and emotional support. After analyzing the show, I then went back to transcribe the relationship-focused interactions.

After reviewing the transcribed interactions, I then recognized the four primary thematic commonalities across the episodes, including: frustration, pride, selfishness, and compromise. The first theme, "frustration," concerns a character becoming negatively overwhelmed with the actions of another character. The second theme, "pride," pertains to a character that, at some point, had some initial reluctance to acknowledge personal wrongdoings. The third theme "selfishness," relates to a character who, at some point, thought of themselves and their ideals as greater than that of another character. The fourth theme, "compromise," addresses a character with the willingness to put personal interest aside to better accommodate another character. The characteristic of "understanding" is a secondary theme within the theme of "compromise." Whenever the characters decide to compromise, they eventually come to a mutual level of understanding. These themes are visible in the communicative nature of the relationships
\end{abstract}


between D'Wayne, Ron, and Whitley. At some point, each of these themes

provide constructive criticism to a character and in return, shape the characters' identify

\section{Season 3 Episode 2, "The Heat is On"}

On October 12, 1989, episode two of season three appeared on television. During this episode, Ron and D'Wayne have a confrontation over how they perceive the way the other person spends money. D'Wayne proclaims that Ron spends money in a limitless manner, while Ron considers D'Wayne to be excessively frugal.

In the beginning of the episode, D'Wayne accuses Ron of using too much toilet paper in the restroom in their apartment. This conflict portrays D'Wayne as having more than a normal amount of concern for household items, while Ron appears to be nonchalant:

D'Wayne: Do me favor, show me how you use this stuff.

Ron: Brother, either I did not hear you correctly, or you need a class in remedial hygiene pronto.

D'Wayne: Huh, please, I'm trying to prove a point. Tear off some paper.

Ron: You know I wonder about you sometimes. May be that last roach bomb, it probably killed off some of your brain cells.

D'Wayne: You're the reason we go through 3 of these a week, you use too much.

Ron: This is a normal amount.

D'Wayne: They wrapped King Tut in less than that.

Ron: Well hey, that's the way we do it in my family,

D'Wayne: Well, mummify your hand when you go home at Christmas.

The personal frame of the communication theory of identity focuses on selfconcepts and the way in which an individual perceives their own self. Yet, the enacted frame focuses on how an individual demonstrates their personal qualities (Jung \& Hecht, 2004). With the personal frame in mind, D'Wayne perceives himself as a good steward over his own finances. Ron believes that he himself is adequately utilizing his household items and financial resources. With reference to the enacted frame, D'Wayne verbally 
announces that he deems himself as financially responsible by spending his money on important living expenditures, including apartment utilities. Ron announces that spending money on important items or experiences is not a complete waste:

D'Wayne: Ron, I don't have the money

Ron: Oh C'Mon mister big summer corporate intern. Start spreading some of that Kinishewa cash.

D'Wayne: I have expenses I didn't have last year. I have to pay for utilities. I have to pay for bus fare. I got to buy you toilet paper. Besides I have to help my cousin Rosy buy her wedding dress.

Ron: What's $\$ 30$ ?

As the episode progresses, Ron insists that the pair invest in purchasing an air conditioner. However, D'Wayne is against the idea and considers the air conditioner as an unnecessary purchase. Ron eventually purchases the air conditioner against the advice of D'Wayne. An argument ensues between the roommates, and they eventually verbally identify their perceived identity for each other in a very aggressive tone. Ron informs D'Wayne that D'Wayne is too cheap far too often:

D'Wayne: Partner, tonight we declare war on heat. Rocky road ice cream and our new deluxe compact fan. It's a little rusty, but... Hey, how'd it get so cool in here? Ron: Because the war on heat has been won, you can take the deluxe fan back to the trash bin you found it in.

D'Wayne: Ron, tell me they were giving these away at the bank instead of calendars.

Ron: Of course not. It was on sale at Radio Robs and brother it's your brand, Kinishewa.

D'Wayne: Couldn't you think to talk to me before shelling out this cash?

Ron: Did you think to talk to me before you brought that rust-blowing machine? D'Wayne: But that was only three bucks.

Ron: I hope so.

D'Wayne: Ron, for two weeks we could have lived with it. But now, we're out a hundred dollars?

Ron: Actually, it was \$176. 90.

D'Wayne: You're unbelievable, I live on a budget.

Ron: There you go beating that budget bongo again.

D'Wayne: Oh, That's good. That's good from Richy Rich

Ron: Richy Rich? Well, I'd rather be Richy Rich than mister tater tot, toilet paper tabulator 
D'Wayne: Are you calling me cheap?

Ron: Yeah, matter of fact, I can see it now. You'll be CEO of Kinishewa Electronics. Just like Howard Hughes, too cheap to get a dollar haircut.

Ron: You'll have dreadlocks down to ya toes boy. The only money you'll spend is on a flea bomb, and then you'll wonder why you don't have a woman.

D'Wayne: Well, I wouldn't set a flea bomb off in your house, it would kill your wife

Ron: I'm not going to look at your rusty scrooge behind for another minute. If you don't like the air condition, you get out.

D'Wayne: Well, you know what, I'm gone

Ron: Good, but you forgot something!

Ron throws rusty fan out the door towards D'Wayne

Even as the pair disagrees, they are able to settle their differences over ice cream.

They are initially stubborn about who will eat from a specific side of the ice cream tub, but they compromise on not allowing their argument impede upon their communication as roommates and friends. D'Wayne and Ron both felt frustration with the antics of the opposing roommate, but they eventually disregarded those differences:

Ron: It's a fire! Call 911. Quick. Where's the phone, we need the fire department. D'Wayne unplugs the smoking air conditioner.

Ron: Good thinking D'Wayne: Thank you.

Ron: I still say you acted like a jackass.

D'Wayne: No no no, you acted like a jackass.

D'Wayne: You want some ice cream?

By the end of the episode, D'Wayne and Ron compromise on their anger and disappointment by eventually sharing ice cream. The communication theory of identity is demonstrated, as both friends are able to communicate their own personal identity and ultimately come to an understanding, while putting their pride and selfishness aside. Communicating their identity clears up any conflict or confusion based on a faulty misunderstanding. For illustration, Ron identified D'Wayne as being cheap, while D'Wayne identified Ron as not being able to properly manage his own funds. Overall, the 
confusion is dissolved once the roommates come to an understanding through verbal communication.

\section{Season 4 Episode 10, "Love Thy Neighbor"}

On November 15, 1990, NBC showcased season four of episode 10 titled, "Love Thy Neighbor." D’Wayne assists Whitley with a project for her marketing course. During that time, D'Wayne asks Whitley why she never wrote him back after he sent her letters while he was away for the summer:

Whitley: I'm talking about for my marketing project? I can't do it all by myself. D'Wayne: Well, that's why God created F's.

Whitley: D'Wayne, you used to take Professor McClaren's marketing class didn't you?

D'Wayne: Yes

Whitley: Then surely you must know somebody that knows something about marketing.

D’Wayne: Yeah, Professor McClaren.

Whitley: D'Wayne would it be that much of an imposition?

D'Wayne: Yes Whitley.

Whitley: I'm desperate, won't you help me?

D’Wayne: You know I will.... For $\$ 6.50$ an hour

Once D'Wayne agreed to assist Whitley with her marketing project, this represented the nature of social exchange theory. Xanthopoulou, Demerouti, and Schaufeli (2009) detail that social exchange theory recognizes the reciprocity within relationships. The give-and-take concept of D'Wayne and Whitley's relationship was showcased once D'Wayne agreed to Whitley's need for help and completed the agreement. For example, Whitley announced that she was in desperate need of D'Wayne's help; soon enough, D'Wayne agreed to help Whitley with her academic project. Furthermore, social exchange theory is applicable as D'Wayne and Whitley's interaction continues, and D'Wayne questions Whitley's prideful demeanor and actions:

D’Wayne: Why didn't you answer any of my letters this summer? 
Whitley: This summer?

D'Wayne: Yes, the three months in the year when it's hot. I wrote you five letters. I wrote you five long letters.

Whitley: I read them all D'Wayne, carefully and lovingly.

D'Wayne: So carefully and lovingly that you couldn't write me a two line postcard back?

Whitley: Wanna know the truth?

D'Wayne: Yeah, where there's a fresh approach.

Whitley: I did write you back, but I didn't mail the letters, because I wanted you to miss me more.

D'Wayne: You're sick.

Whitley: I was sick and I was playing games, but all that's changed now.

D'Wayne: Not since I've last checked.

Whitley: What are you talking about?

D'Wayne: I'm talking about kissing my best friend in my face

Whitley: Oh that.

D'Wayne: Yes that. Playing me and Ron off each other. That's deep, Whitley

Whitley: I thought I had to play games to get you, D'Wayne. But I swore I would never play them once I had you

D'Wayne: No no, you don't have me yet.

D’Wayne vocalizes his discontent and frustration with Whitley's purposeful avoiding of his letters for her own selfish benefit. Social exchange theory acknowledges both implicit and explicit expectations that relationship members may have for one another (Xanthopoulou, Demerouti, and Schaufeli, 2009.) Specifically, D’Wayne had implicit expectations that Whitley would write him back while they were separated by distance. D'Wayne's frustration stemming from Whitley's lack of response is a depiction of the constant ups and downs of their relationship. Despite D'Wayne's frustration with Whitley, he compromises and allows his relationship with Whitley to flourish:

Whitley and D'Wayne later cuddle on the fire escape. Whitley: I'm just waiting for a pigeon to descend upon us and interrupt us this time

D'Wayne: There aren't going to be anymore interruptions

Whitley: One more thing. These are for you, addressed to Japan

D'Wayne: Probably took you all semester to write these.

Whitley: I told you I wrote them this semester.

D'Wayne: I know, I know. I can't wait to read them Whitley: Well you have to. 
Whitley goes in for a kiss.

D'Wayne: Woah Woah Woah, on more thing..... I love you too.

Whitley and D'Wayne kiss

Both parties express their love for one another through their verbal

communication. Pride and frustration are put to the side in order to keep their relationship

positive. Notwithstanding their previous disagreement and the feelings of

disappointment, Whitley and D'Wayne acknowledge their mutual love. Once D'Wayne

and Whitley mention their love for each other, they illustrate the "enacted identity" of the

communication theory of identity (Jung \& Hecht, 2004). The enacted identity focuses on

the expression of personal traits; this identity frame is exhibited through this specific

interaction between D'Wayne and Whitley.

\section{Season 5 Episode 9, "To Tell The Truth"}

The "To Tell the Truth" episode of $A$ Different World aired on November 14,

1991. During this episode, Whitley aggravates D'Wayne to the point that he goes out

with another woman. While at a work function, D'Wayne becomes utterly frustrated with

Whitley and her antics that publicly embarrassed him in front of his colleagues and

friends:

Whitley and D'Wayne attend a dinner and Whitley interrupts as D'Wayne is sitting around and conversing with his colleagues

Whitley: *pats D'Wayne on the thigh as a cue to sit aside and talk with her. Excuse me.

Whitley: Pookie, I'm ready to go. We have a lot to talk about. When my parents get here, we won't have time to be alone and play footsie.

D'Wayne: Baby, there's going to be plenty of time for that.

Whitley: I am tired of hanging around this parade of pocket protectors

D'Wayne: Oh, wait a minute now. This is no more boring than those artsy fartsy things you drag me too.

D'Wayne: It's important for me to mingle with other faculty and students. Babe come on.

Whitley: You just don't care D'Wayne! You just don't care about your own engagement party. 
D'Wayne: What, do you wake up whining?

Whitley: Not when I've been treated right the night before.

D'Wayne pour punch an accidentally spills the punch on Whitley's blouse in the process

Whitley: *Screams My blouse! It's ruined for life!

D'Wayne: I'm sorry, I'll buy you a new one.

Whitley: It's not the same D'Wayne. You are not helpful at all. You are totally insensitive to my prenuptial needs.

Whitley walks off

D’Wayne:Whitley!! Whitley!!

In this episode, Whitley exposes her selfishness and initially refuses to compromise with D'Wayne. For example, Whitley prefers to leave D'Wayne's networking event and go home to finish planning their engagement party and upcoming wedding. Whitley then proclaims that D'Wayne is oblivious to her premarital needs. This public conflict is indicative of D'Wayne and Whitley's common conflict in their relationship. Whitley believes that D'Wayne fails to provide her with the emotional support that she deems to be integral to the success of their engagement party. According to Feeney and Collins (2015), the presence of emotional support in relationships can assist in disbanding any complicating issues. When faced with difficulties, relationships are supposed to withstand adversity through the strength of the emotional support.

Simultaneously, Whitley and D'Wayne both feel as if the other relationship partner is not providing necessary support. This leads Whitley to cause a huge spectacle; in return, D'Wayne acts on his attraction to the other woman also present at the event, Lisa. The following scene acknowledges the danger of a relationship partner receiving emotional support from someone outside of the relationship. For example, seconds after spilling a drink onto Whitley's clothes, D'Wayne spills food onto Lisa's shirt. However, Lisa's reaction is one of understanding. Shortly after meeting at D'Wayne's work event, D'Wayne and Lisa set up a time for the two of them to meet over dinner: 
D'Wayne then runs into Lisa, accidentally smashing Lisa's food onto her shirt D’Wayne: Oh Damn! I'm sorry.

Lisa: It's ok. Really.

D'Wayne: I'll pay for it. I got my wallet.

Lisa: Listen, calm down. It's not necessary. I'm sure it'll come out. Hopefully

D'Wayne and Lisa are out on a date

D'Wayne: I had a really good time.

Lisa: Me, too

D'Wayne: You know, my roommate says I should not have gone out with you.

Lisa: Well, you do have a girlfriend.

D'Wayne: So why are well here?

Lisa: Because I find you attractive and you invited me, remember?

D'Wayne: That's right, I invited you. I'm guilty as charged.

Lisa: Listen, there is no rule that says men and women can't be friends. And if women were friendlier, we'd all have better insight to the opposite sex.

D'Wayne: Or maybe just each other.

Lisa: Hmm, how would your fiancée feel about that?

D'Wayne: I haven't given that much thought.

Lisa: Well maybe you should. I'm sure she's wondering where you are and who

you're with. And why you're with that person.

D'Wayne: She offered to buy me a beeper.

Lisa: If I were her, so would I.

Whitley's friend, Kim, walks into the restaurant and spots D'Wayne and Lisa and walks out before being spotted by D'Wayne and Lisa

Kim: I stopped by the Mirage last night. What were you doing there?

D'Wayne: I was minding my business. She is just a friend.

Kim: Well, you know I had to say something right? It's not every day you see

your friend's fiancé holding hands with anything woman. I'm just looking out for Whitley

D'Wayne: Well, I can respect that.

Kim: So does Whitley know about this friendship?

D'Wayne: She was there the night we met.

Kim: I repeat, does she know about this friendship?

D'Wayne: Look Kim, Whitley has been my world for the last year. I have given this relationship my all. I don't know what else to do, I'm tapped out.

Kim: Be honest.

Ultimately, D'Wayne looks to find his emotional and social support somewhere

else, even in the company of another woman. D'Wayne immediately recognizes Lisa's

response to him spilling food on her shirt, especially since Whitley gave the opposite

response in a similar situation. Feeney and Collins (2015) explain the importance of 
reframing adversity once it appears in a relationship. D'Wayne does not reframe Whitley's embarrassing outburst; instead, he accepts it as it happened and allows it to push him to the limit. Instead of being dishonest about his date, D'Wayne is very forthcoming when he has a conversation with Whitley's friend Kim. What is striking, however, is that despite being on the date, D'Wayne identifies that he is conflicted with his actions. For example. D'Wayne makes a joke with Lisa about figuratively being "guilty as charged," when he really does begin to feel remorseful about his actions. Furthermore, D'Wayne admits to Kim that he is figuratively fatigued from giving his all to his relationship with Whitley. D'Wayne's personal identity is that of a man that has continued to invest his time into a woman that simply has a different cultural background and frame of reference compared to himself, which continues to cause conflict in their relationship. Comparatively, D'Wayne subtly verbalized his enacted identity to Lisa and explicitly to Kim. When communicating to Kim, he expresses his premarital frustration and admits to running low on intrinsic encouragement to support his relationship and a desire to keep it going.

Xanthopoulou, Demerouti, and Schaufeli (2009) describe how relationship partners eventually create a relationship that contains "trusting, loyal, and mutual commitment" (p. 877). D'Wayne and Whitley's relationship has moments when it corresponds with the aforementioned characteristics. However, this specific situation is a perfect example of the consequences that stem from a relationship partner feeling that fatigue from giving more than what they can offer. As a couple that is journeying towards marriage, D'Wayne and Whitley have implicit expectations that they will not put themselves in compromising physical or communicative situations that have the potential 
to harm their relationship. D'Wayne nullifies this expectation when he cultivates his interest in Lisa and takes her on a date. This conflict acknowledges that social exchange theory rightfully makes a valid point that relationships are full of constant give-and-take. The communication theory of identity allows us to view D'Wayne as identifying himself as a relationship partner headed towards marriage, but also as a fiancé that has uncertainty with constant frustration regarding his relationship.

\section{Season 5 Episode 10, "Do You Take This Woman”}

During this episode, D'Wayne admits to Whitley that he took another woman to dinner after their disagreement. This admission of guilt came untimely as D'Wayne reveals this information right before he and Whitley host a celebration for their premartial engagement. Whitley becomes frustrated with D'Wayne's decision to entertain the idea of spending time with another woman. D'Wayne only made this decision after he became frustrated with Whitley's consistent selfishness when she focuses on herself:

Whitley: You went to dinner with another woman?

D'Wayne: Yes, but nothing happened Whitley.

Whitley: So, why you're telling me?

D'Wayne: Because I wanted to be honest with you.

Whitley: That is the worst I've heard.

D'Wayne: Bunny that's the truth.

Whitley: Don't call me Bunny, and you better not have taken that tramp anywhere better than Micky D's or HoJoes.

D'Wayne: Whitley, she's not a tramp.

Whitley: Oh, now you're defending her.

D'Wayne: She's a graduate student studying molecular biology.

Whitley: You're dumping me for some egghead.

D'Wayne: I'm not dumping you Whitley.

Whitley: So you're not attracted to her?

D'Wayne: That's not the point.

Whitley: Yes it is.

The following scene shows the toast \& cheers portion of the engagement

Whitley: D'Wayne?

$$
\text { party }
$$

D'Wayne: Bunny, I don't know what to say. 
Whitley: Ok, Um.

Whitley: It's so nice to look out and see all of you here tonight. All of the people that I love and all of the people that love me. And some of those that aren't quite sure how they feel about me. I'd like to thank ya'll for coming tonight, But I'm not going to be getting married.

D'Wayne: Whitley!

Whitley walks off and D'Wayne chases after her

D'Wayne: Whitley, can we talk about this?

Whitley: There's nothing to talk about D'Wayne. There was a decision to be made and you couldn't make it.

D'Wayne: But, I still love you. Sometimes this is going way too fast for me, but my father says that everybody has doubts.

Whitley: Doubts D'Wayne, not dates. I'm not meant for you.

D'Wayne: No, that's not true. Sometimes, you're too much.

Whitley: I want to be your one and only D'Wayne, are you ready for that?

*Silence and Whitley takes off her ring and gives it back to D'Wayne

Some of the previous episodes showcase D'Wayne vocalizing his frustration with Whitley. However, this episode shows an opposing view of this relationship and focuses on Whitley being upset with D'Wayne. This back-and-forth type of relationship is repetitive and appears in many of the plots within multiple episodes. This specific episode relates to D'Wayne struggling to negotiate this identity as an engaged man that is in love and ready to become married or as someone that is fed-up with his needy fiancée. Whitley recognizes D'Wayne's transitional identity and calls off the engagement as a representation that she is not willing to compromise by marrying someone whom is not completely secure with commitment.

Feeney and Collins's (2015) stance on emotional and social support documents that a relationship partner should provide the necessary emotional support to rid the relationship of any discomfort that could potentially have a negative effect on the relationship. Confidence and support are monumental to cultivating and maintaining a strong relationship. Once D'Wayne entertains another woman and notifies Whitley of this encounter, he voids the strong emotional support and confidence needed in a relationship. 
Whitley loses her confidence not only in D'Wayne, but also in their relationship and their desire to be married. This stems from Whitley no longer feeling the security and comfort of knowing that D'Wayne has a romantic interest only in her. The lack of emotional security negatively impacts the social support that was once pervasive in Whitley and D'Wayne's relationship.

\section{Season 5 Episode 13, “Just Another Four-Letter Word”}

On January 2, 1992, NBC aired season five episode 13 titled "Just another FourLetter Word." This episode focused on the relationship between D'Wayne and Ron. As shown in a previously discussed episode, Ron and D'Wayne feud over finances and unpaid bills. However, D'Wayne reaches an all-time high level of frustration with Ron's inability to manage his personal financial responsibilities, especially those that concern the roommates' living situations. Once Ron does not pay the electricity bill, the power shuts off while D'Wayne is working on his thesis, causing him to lose his work:

D'Wayne: Mr. Johnson, I'd like to introduce you to some friends of mine who have been looking for you the last few months. Take a look at mister phone bill, mister electric bill, and rent.

Ron: Look, I paid the phone bill.

D'Wayne: No, you paid the phone bill with a rubber check.

D'Wayne: Now you messing with my credit Ron

Ron: Don't burden me with these petty details. I got to keep the band's morale up till we win the Rockward Records band competition.

Ron: Till then, I'm sort of in the red

D'Wayne: In the red? What happened to the money that your Pops sent you once you got that diploma?

Ron: That paid for the demo that got us into the finals baby!

D'Wayne: You get on the phone and you call that man and you beg for more money boy!

Ron: Let me explain something to you. I win this record competition, I get a recording contract and we all get paid.

D'Wayne: Ok, let me explain something to you. Mr. Gaines don't get his money, you out of the apartment!

Ron loses the band competition and D'Wayne arrives to the event upset. D'Wayne: Ron! 
Ron: Mi compadre, partner.

D'Wayne: Don't partner me, you no-rent-bill-paying, electric-bill-dodging doofus. I was sitting at my computer working on my thesis, when you know what happened?

D'Wayne: The lights when out then the power went off. Do you know how much information I lost?

Ron: Well, I never did understand those computers.

D'Wayne: No? Ok, good. I'll tell you how much. I'll tell you how much. I lost enough to kick your free loading butt out, you evicted man!

Ron: Evicted?

D'Wayne: Aye, you want me to spell it for you? E-V-I....

Ron: I know how to spell it.

Ron: You know kicking me out's not going to pay the other half of the rent. D'Wayne: Aye But it'll make me feel a lot better man,

Ron: Feel better? Oh so you all large like that D'Wayne? Kick me out on the most devastating night of my life? We lost the contest

D'Wayne: Oh, so now I lose any chance at getting my half of the rent from you.

Ron: I'm not down and out for the count. Tomorrow I'm going to send my tape to Motown, Columbia, Quincy himself.

D'Wayne: Alright, while you're at the post office. See if they got any job openings.

Ron: I've got a job. I'm a musician.

D'Wayne: Aye man, I mean a job that pays. Wake up and smell your empty bank account fool!

Ron: Well, if you were any real kind of friend, you'd carry me a little longer. D'Wayne: Oh, Aye. I am your friend. I'm going to carry your bags to the curb. That's it.

Ron plays his drums on campus to get donations to be able to pay his rent and D'Wayne walks up. D'Wayne takes Ron's donations from the hat set up to hold the donations

D'Wayne: Keep playing keep playing.

Ron: So the vultures come to pick at my flesh. Well, I'm not dead yet.

D’Wayne: Hey, I supported you Ron.

Ron: I have more support at a skinhead rally. Friends don't bail out on you at the first sign of trouble

D'Wayne: Aye, wait a minute. Nobody bailed out on you. You bailed out on yourself. I kicked you out because you need it. I just wish I had on my steel toe boots.

Ron: What you don't understand is that I have to make sacrifices for my music. D'Wayne: Well I don't.

Ron: Music is my dream and dreams keep you alive

D'Wayne: And money keeps you in the house. Get a job

Ron: Then I won't have time for my music

D'Wayne: Yes! You can do that too. T-O-O as in additional to, conjunction with 
Ron: Well, I guess I can crawl back to Jalisa. That job pushing a mop for $\$ 7.50$ an hour

D'Wayne: Well, if you do that, I guess I could dig a little deeper in my heart to come up with some extra money for rent to carry you for another month. D'Wayne: We'd have to eat beans though. They'd be cold. The gas is off. Ron: Ah that's beautiful! That's so sweet!

Goes to give D'Wayne a hug and D'Wayne playful pushes him away D'Wayne: Aw no man. Get off of me man.

According to Tiny Toomey's (2005) explanation of identity negotiation theory, Ron's negotiated identity in this specific episode fulfills the first assumption of the theory. The first assumption declares that belonging to a specific group through communication can cause the membership to have a sentimental meaning to an individual. Specifically, the text serves as evidence that Ron's membership to his band has extreme value to him and carries a special meaning. So much so, Ron is willing to go without money for the time being, because he believes that his passion for music and connection to his band will soon bring financial reward, even if it means that he was to go without resources for a period of time. Similarly, D’Wayne belongs to a specific group that has a personal meaning to him; this group identifies as academic scholars. D'Wayne is in pursuit of a higher degree from Hillman College and proudly carries his identity as an academic scholar. D'Wayne's identity is in jeopardy once the power goes out while completing a highly regarded scholarly project, an academic thesis. The thought of losing this identity pushes D'Wayne into a fit of anger and frustration.

Sadly, Ron's passion for music is not enough to keep the lights on in the apartment he shares with D'Wayne. Ron admitted to D'Wayne that he feels he has to "carry him" in their roommate relationship, in the sense of paying bills that Ron is unable to pay. Jung and Hecht's (2004) third frame of the communication theory of identity focuses on relational identity, with a subpart that recognizes that a mutual relationship 
between two people can birth a shared identity for a group. In this episode of $A$ Different World, Ron and D'Wayne's shared identity is one of kinship that offers forgiveness even in moments of frustration. D'Wayne's forgiveness embodies the theme of compromise and dissolution of pride, since Ron had immense pride regarding his group. In a broader sense of the plot of this episode, D'Wayne's initial anger and confrontation with Ron in conjunction to revoking his initial eviction, satisfies social exchange theory.

According to Feeney and Collins (2015), their idea of a relational catalyst partially focuses on "the perceptual assistance in the viewing of life opportunities" (p.24). The scholars detail that friends can provide the necessary encouragement for their friends to pursue their goals, despite any uneasiness on behalf of the owner of the goals. Notwithstanding D'Wayne's initial anger, D'Wayne's level of forgiveness and permission for Ron to continue his dreams as a musician relates again to the relational catalyst concept. Another portion of the relational catalyst acknowledges a relationship partner creating an environment to allow the other part to utilize the space and opportunity needed to work towards successful goal execution. D'Wayne provides the social support to allow Ron to not only have a home in which to live, but Ron will have less worries as he perfects his craft as a musician. Ron and D'Wayne's communicative interaction aligns with what Feeney and Collins (2015) call a "relational catalyst" while providing a relationship partner with the verbal motivation to successful attain their accomplishments: Ron's ability to fulfill his goal of working towards perfecting his musical abilities is evidence of the relational catalyst's utility. 


\section{Season 5 Episode 25, "Save the Best for Last"}

On May 14, 1992, NBC aired season five episode 25 of $A$ Different World, titled "Save the Best for Last." This episode depicts Whitley preparing to marry her new fiancé, Byron Douglas. An estimated six months past her break up with D'Wayne, Whitley is now ready to marry her new love, Byron. Her preparation ends when D'Wayne interrupts the wedding and asks Whitley to marry him instead of Byron. Surprisingly, Whitley agrees to marry D’Wayne instead of Byron and literally does so during the marital ceremony:

As Whitley prepares for her wedding to Byron Douglas, D'Wayne's name is mentioned in the conversation with her mother Mrs. Gilbert.

Mrs. Gilbert: Anything must be better than those yahoos, the Waynes Whitley: Mama, I learned a lot from those yahoos.

Mrs. Gilbert: Really, what? How the other half shouldn't live?

Mrs. Gilbert: Darling, you really should feel very relieved, because you've done much better for yourself. I mean Byron is an entrepreneur, he's a senator, he's a businessman.

Mrs. Gilbert: You are going to make a wonderful first lady.

Whitley Aren't you jumping the gun a little bit?

Whitley's Mom, Mrs. Gilbert, surprises Whitley with a bracelet

Whitley: Mama, D'Wayne came to see me last night.

Mrs. Gilbert: Did you pick your garter for today? Do you want the satin and lace, or you want just the plain one?

Whitley: Did you hear me Mama?

Mrs. Gilbert: I do not wish to discuss that lily-liver cad that broke my baby's heart and also ruined one of my better dinner parties.

Whitley: The breakup wasn't all his fault mama.

Mrs. Gilbert: Whitley Gilbert, today is your wedding day. There should be only two men on your mind; Byron because you love him and your father because he's paying.

Mrs. Gilbert: Now I do not want to hear another word mentioned about that other individual. Is that clear missy?

Whitley: Yes Mama.

Whitley walks down the aisle with Byron Douglas, but D'Wayne interrupts the as minister asks if anyone objects to the wedding

D'Wayne: Will you? Whitley, I love you and if you'll have me, I want you to be my wife!

Byron: What the hell are you doing?

D’Wayne: I'm sorry. Byron, I love her. 
Mrs. Gilbert: Die! Just die!

D'Wayne: Will you have me D'Wayne as your lawfully wedded husband? From this day forth to have and to hold? For richer for poorer?

D’Wayne: Baby please! Please!

Whitley: I do!

Whitley: I'm sorry Byron.

\section{Whitley turns to Byron}

Whitley runs to D'Wayne and gives him a kiss.

Minister: Is anybody getting married here today?

D'Wayne: Yes, we getting married. I'm D'Wayne.

Minister: By the power invested in me, I now pronounce you...

Whitley views herself as being more understanding about her breakup with

D'Wayne. Jung and Hecht's (2004) communication theory of identity emphasize that the personal identity frame is made up self-concepts; the enacted identity focuses on how the personal characteristics are communicated. Whitley and D'Wayne both confess their love for each other with relation to their self-concept of the personal identity frame. Although they terminated their engagement in a previous episode, they deeply love each other to the point that it constructs their identity. For example, Whitley loves D'Wayne to the point that she is willing to end her relationship with Byron in order to progress her relationship with D'Wayne. Similarly, D'Wayne loves Whitley to the point that he is willing to interrupt Whitley and Byron's wedding. For example, D’Wayne yells, “I'm sorry Byron, I love Whitley," furthering his interruption by proclaiming to Whitley, "baby please, please?" The communication theory of identity also contains the relational identity comprised of a joint identity that can be derived from a relationship. Ultimately, Whitley and D'Wayne's relational identity breed its own collectively identity. Once Whitley and D'Wayne understand that they both have an unending love for each other, they communicate this love in order to satisfy their relationship. This communication 
leads Whitley and D'Wayne to marry at the exact day, time, and ceremony that was supposed to belong to Whitley and Byron.

Whitley and D'Wayne both rid their identities of any pride or selfishness during their wedding ceremony. They are able to come to a compromise and an understanding in order to move forward in their relationship, despite having once called off their engagement. The eventual marriage between Whitley and D'Wayne indicates the reciprocity between the two. Xanthopoulou, Demerouti, and Schaufeli's (2009) social exchange theory concedes that a relationship will ultimately progress and formulate into a "trusting, loyal, and mutual" bond (p. 877). The aforementioned characteristics are confirmed present between Whitley and D'Wayne once the minister announces, "I now pronounce you," which signifies that the couple is now legally and officially married.

\section{Season 6 Episode 3, "Interior Desecration or Sofa, So Good"}

NBC premiered season six episode three, titled "Interior Desecration or Sofa, soGood" on October 8, 1992. By this episode, Whitley and D'Wayne have married and moved into a new home together. As a couple, they face the issue of deciding whose set of furniture will be used to furnish the home. Whitley's selfishness and unwillingness to compromise is the main issue that cultivates D'Wayne's frustration in this episode:

Whitley and D'Wayne sort through their collective belongings as they decide what is to stay in their new home.

Whitley: D'Wayne, D'Wayne, I think we need to pare down a bit

D'Wayne: Yeah, I guess we are a little crowded

Whitley: Ok, I'll tag the things we don't need and Ron can get rid of them

Ron: For an additional fee of course.

D'Wayne: Of course.

Whitely tags all of D'Wayne's items.

D'Wayne: Woah Woah Woah, baby what are you doing?

Whitley: A public service

D'Wayne: This couch is very special to me. Sentimental value 
D'Wayne: Now baby, wait a minute why do you want to get rid of my loveseat here?

Whitley: Does horrific eye sore mean anything?

Whitley: I just thought that my stuff has seen a little less wear and tear.

D'Wayne: But it's pink. Sweetie I don't think I can live with a pink couch.

Whitley: Can you try?

\section{Whitley give D'Wayne a seductive look}

D'Wayne: Oh I think you may be able to convince me a little more.

D'Wayne: A wait a second, hold it. Why is all my stuff tagged for the furniture grave yard?

Whitley: Don't be ridiculous D'Wayne. What's mine is yours and what's yours is gone.

D'Wayne: Whitley please, you have to give up something.

Whitley: Ok Pookie, listen to this. How about I take the Wayne name, and then can I keep some of my stuff?

D'Wayne: You know what? You have a big problem baby. Such a big problem.

Whitley: What's the big problem?

D'Wayne: You have a control problem

Whitley: I'm being negotiable

D’Wayne: All you want to do is control everything.

During this conversation, it is clear that Whitley is more than reluctant to throw

away her own personal belongings and then furnish the home with D'Wayne's furniture.

Whitley identifies herself as being negotiable, while D’Wayne accuses Whitley of being

overly controlling. Jung and Hecht (2004) document that the personal identity frame of

the communication theory of identity relates to personal self-concept. Once Whitley

announces that she believes that her behavior is indicative of a negotiable personality, she

identifies the way in which she views herself. Furthermore, the enacted frame of the

communication theory of identity is also applicable, especially since this frame focuses

on how the self-concept is communicated through verbal communication and, sometimes,

physical action. Whitley's actions and communication to D'Wayne enact what she

believes to be positive assistance to their dilemma of house furnishing. However,

Whitley's actions can easily be perceived and labeled as pure selfishness. 
When possessively choosing furniture with D'Wayne and deciding what to discard, Whitley declares, "What's mine is yours and what's yours is gone." This statement alone is evidence of Whitley acting selfishly towards her husband. Whitley then attempts to perform her own version of a compromise: She proposes taking D'Wayne's last name, Wayne, in return for keeping her furniture. This interaction only frustrates D'Wayne to the point of acknowledging that Whitley has control issues that are visible in this episode:

\section{Ron walks in and interrupts}

Ron: Listen man, is it alright if I just bunked on your sofa for a couple nights? D'Wayne: Yeah man, you can stay with us till you find your own place. Whitley: Uggh.

D'Wayne: Ugh, he'll stay on my couch

Whitley: It'll be sitting on the curb.

D'Wayne: Says who?

Whitley: Did we not decide that D'Wayne?

D'Wayne: Aye you know what! All bets are off Whitley! All bets are off! Whitley: Ok fine hunny. I'll wash my hands of the whole thing. You go through everything, you pick out what you want and I'll just live with it like a good little wife.

D'Wayne: Fine. Ron, get rid of this, get rid of that. And please rid get of this. D'Wayne: If you have anything to say, you say it. I'm tired of you and your manipulating passive-aggressive Marta attitude.

Whitley: Thank you Dr. Freud, I'll take my severe psychological problems elsewhere

\section{Whitley storms out of the house.}

D'Wayne: You take all of her stuff and you get rid of it. I don't care where it goes, just take off her stuff and get rid of it.

\section{Whitley.}

D'Wayne becomes extremely frustrated and vocalizes his anger towards

As D'Wayne heads off to the car, Whitley runs to grab the rest of her belongings from the apartment storage and tosses D'Wayne's belongings, including his lamp, out the window and replaces it with her own lamp.

Whitley: Hi!

D'Wayne: What are you doing?

Whitley: Hmm?

D'Wayne: Where's my lamp? This lamp wasn't here before? 
Whitley: That lamp's always been there D'Wayne.

D'Wayne: Whitley, this lamp, the phone, and the picture! Where did you stash all this stuff?

Whitley: I can't remember any other lamp.

D'Wayne: Ok! You're lying and you're sneaky. You wanna be petty? From now on, you only use your stuff and I only use mine. That way it'll be separate, but equal

Whitley: That is ridiculous. You are over reacting

D'Wayne: I brought the bed, I get the bedroom, you make other arrangements.

Whitley: So, I brought the toothpaste. Mr Plaqueman

D'Wayne: Well, I brought the toilet paper, so you have to make other arrangements

Whitley sits in brags to her friends about the power she has over D'Wayne Whitley: You don't understand Kimmy, wait till it happens to you. I have to give up everything. My style, my taste, my name. What is life?

Kim: Your foolish pride!

Whitley: My foolish pride has gotten me plenty. I can play that man [D'Wayne] like lotto. We all know it. He'll come crawling back on his knees any minute. I'll have him marching to my tune.

D'Wayne appears as Whitley is sitting with her friends

D'Wayne: Whitley, listen to me. I'm not going to spend another night like last nite. Ok. I can live without furniture, I can't live without you, you're my wife. Let's go with this thing out. C'mon.

Whitley is not afraid to communicate her selfishness and identity thereof, especially when conversing with her friends. For example, Whitley tells Kim that her own personal "foolish pride" has allowed her to be able to play D'Wayne "like the lotto." Whitley's selfishness is repeatedly the reason behind many of her arguments with her husband. D'Wayne and Whitley both have the implicit expectations of compromising with each other on furnishing their home. This situation mirrors Xanthopoulou, Demerouti, and Schaufeli's (2009) explanation of social exchange theory in that the characters acknowledge the expectations of a relationship (Xanthopoulou, Demerouti, Schaufeli, 2009). Whitley and D'Wayne's perception and definition of compromise has clear differences. In this episode, there is a lack of explicit expectation on how much they are both expected to offer up as a compromise for the other spouse. This lack of clarity 
triggers frustrations with both D'Wayne and Whitley. Nevertheless, D'Wayne is rather selfless and communicates to Whitley that he wants them to work out their differences. This form of interaction reiterates the thematic appearance of the characteristic of compromise. Although Xanthopoulou, Demerouti, and Schaufeli's (2009) explanation do not explicitly mention compromise within social exchange theory, they do mention uneven exchange and the problems that persist from these exchanges. The absence of clarity and the presence of uneven exchange repeatedly causes confusion between Whitley and D'Wayne.

\section{Season 6 Episode 12, "Occupational Hazards"}

On December 3, 1992, NBC aired season six episode 12, titled "Occupational Hazards." Whitley has been laid off from a previous job and has an upcoming interview. Soon enough, Whitley determines that she is in need of new attire for her interview, yet D'Wayne announces that they are not in the financial position to buy any new clothes, especially new and expensive clothes. D'Wayne travels out of town for a work trip, leaving Whitley to sneak and purchase a $\$ 700$ suit that she stains before she can return the item. Whitley not only buys a $\$ 700$ suit that cannot be returned for a refund, she also uses D'Wayne's credit card for the purchase, unbeknownst to her husband:

Whitley: D'Wayne this is the most important interview since I've lost my job. Heresford Auction house is world renowned. What do you want me to wear to this interview, your boxer shorts?

D'Wayne: That might guarantee you the job baby.

Whitley: Be serious. I need a new outfit

D'Wayne: Stop it Woman, we can't afford it right now

\section{D'Wayne prepares to go out of town}

D'Wayne: Baby I love you, good luck on the interview, I'm going to call you tomorrow. And don't buy anything. No promise me

Whitley: I promise

D'Wayne: You promise?

Whitley: I promise 
D'Wayne: Say it again

Whitley: I promise!

Whitley closes the door and reveals that she had her fingers crossed behind her back

Whitley uses D'Wayne credit card to buy a new suit for the interview and accidently spills wine on the suit before she can return the suit

D'Wayne returns home from his business trip and overhears

Whitley making cold calls as a call salesperson

D’Wayne: Hello!

Whitley: D'Wayne, how long have you been standing there?

D'Wayne: Long enough to wonder what the hell you're doing. The place looks different, did you move a lamp or something?

D'Wayne: Where the sofa Whitley?

Whitley: I didn't get the job and I tried so hard. Poor me

D'Wayne: No no no, poor you nothing. Where's the sofa Whitley?

Whitley: Did I neglect to tell you that I had to sell the sofa for \$200, so now I owe you five. Go ahead and yell at me

D'Wayne: You, no I'm not going to yell. That would only make you feel better

Whitley: But Pookie, I went behind your back and got your credit card and brought a $\$ 700$ suit

D’Wayne: \$700! Whitely! \$700!

Whitley: But now I owe you five...

D'Wayne: I'm not going to yell! Move move move!

Whitley: But I'm sorry Pookie! I'm dialing Pookie. I'm going to pay you back every penny

D'Wayne goes into the kitchen and screams when he realizes the refrigerator is gone

D'Wayne: Whitley, Where is the refrigerator?

Whitley: 80 bucks, we're down to $\$ 420$.

This interaction focuses on explicit expectations that D’Wayne has for Whitley; these expectations are representative of the same sort of expectations discussed within social exchange theory (Xanthopoulou, Demerouti, \& Schaufeli, (2009). D’Wayne is under the impression and expects that Whitley will keep her explicit promise of not purchasing interview attire, especially since any new attire could potentially be financially burdensome. These expectations are violated once they are not properly fulfilled. For example, after Whitley decides to make her purchase, D'Wayne's expectation of her financial responsibility is shattered. D'Wayne becomes frustrated with 
Whitley's shopping excursion and selfishness when she also uses his credit card to make the purchase. However, Whitley puts her pride aside and admits that she went against her pact with D'Wayne. After the announcement, Whitley attempts her own version of a compromise by selling their home furniture and taking a job as a telemarketer. Once again, A Different World captures Xanthopoulou, Demerouti, and Schaufeli's (2009) declaration of relational uneven exchange - or compromise - of social exchange theory.

\section{Season 6 Episode 17, "When One Door Closes"}

On May 8, 1993 NBC aired season six episode 17 of $A$ Different World, titled "When One Door Closes." This is part one of two episodes of the last season that focus on Whitley and D'Wayne moving to Japan. D'Wayne's job offer comes after he creates a video game that Kinishewa desires to purchase. Ron provided D'Wayne with concepts to actually use for the creation, but D'Wayne refuses to pay Ron for his ideas that garnered the interest of Kinishewa. Ron considers suing D'Wayne for proper financial compensation since he contributed to the success of their joint effort. These two episodes lead to the end of the television series. During this episode, D'Wayne accepts a job offer with Kinishewa that is located in Japan. Whitley finds out that she is pregnant, but waits to make the announcement to D'Wayne:

D'Wayne is on the phone with bill collectors as Ron is present Ron: It pains my ears to hear that my favorite coupon couple is struggling, but maybe I could spot you the money. You know I had a great weekend at the club. D'Wayne: Well thank you partner. I don't need a nickel for a gumball, I need \$200 to pay my phone bill.

phone

Ron gets up and leaves as D'Wayne is still on the

D'Wayne: Declined!? Well aye, let me tell you something, you on the phone with the man of the house now dude. Yeah, well, how about I come down there and reach out and touch somebody with my fists. Hello?

D'Wayne: Damn, I hate being broke!

D'Wayne: Thank you for the crumbs Ron! 
D'Wayne picks up Ron's plate and notices that Ron purposely left $\$ 200$

underneath the plate

D’Wayne: \$200 my brother

Ron and D'Wayne are in the kitchen as D'Wayne is playing a handheld game system

Whitley: I cannot compete with this stupid contraption.

Ron: Whitley, how can this game be stupid when every kid in America wants one. D'Wayne: What they need to do is develop a cartridge that teaches grammar Ron: Yeah, make it fun like baseball. See, the noun can be the batter and the pitcher can be the verb.

D'Wayne: And every time you get an answer right, it can be like a homerun

\section{D'Wayne and Ron meet up for lunch}

D'Wayne: I've been working night and day on the computer program that is going to skyrocket elementary education. I'm talking pure genius Ron, and Kinishewa, they want to buy it!

Ron: Congratulations partner! Ayeee. I always know you'd have your name lit up across computer screens someday.

D'Wayne: No no no, it's bigger than that. Kinishewa is crazy about using baseball to teach grammar. All I have to do is make it through one more meeting with the big wigs. And if it goes well in there. I'm coming out with the fat pockets like PoPo-po-Ping!

Ron: What a minute. You know what this means for us? WE can finally be business partners.

Ron: Me with my high concepts and you with your little scientific methods. This is a million-dollar match made in heaven. Oh this is exciting!

D'Wayne: Ron Ron Ron. Hold it Hold it hold it. Business partners?

Ron: Alright. Wayne and Johnson. My motto is no need to be petty when you ching-ching! About to get paid

D'Wayne: What does my computer program have to do with you?

Ron: The baseball game was my brain child, remember?

D'Wayne: Oh hold on baby, you have to have a brain to have a brain child

Ron: What does that mean? I came up with the whole thing.

D'Wayne: Oh Ron. No offense, but the guy that was watching Ben Franklin fly

the kite doesn't get cut into the electricity deal

Ron: Maybe that's because Ben stole Ol' boy's kite. Now let the record show it was my idea

D'Wayne: Ron, the idea came from a simple conversation we had

Ron: NOT THEE IDEA, my idea

D'Wayne: You wouldn't know a good idea if it jumped up and slapped you in the face. Boy what are you talking? You know what, if it means that much to you, I'll give you $5 \%$, but I'm going to be able to carry you this time

Ron: When have you carried me?

D'Wayne: Ron, come on. We both know that every time something good happens to me, you get jealous unless you get to tag along. Ok, I'm not going to be able to do it this time baby. 
D'Wayne: I been carrying you since me met. Ron, what do you want?

Ron: You think I'm jealous of you?

D'Wayne: You know what? I think you're crazy. Let's drop it.

Ron: Naw naw naw. It's too late to drop it. Let's put our cards on the table, brother.

D'Wayne: You wanna get real?

Ron: Please do.

D'Wayne: Alright. Well, I always got finer women than you. I got better grades than you. I graduated before you, I got married before you. I got married to the woman you sweated throughout your whole college six year career. Shall I go on? You want me to go on with this?

Ron: Naw. Let me go on for a while. See, the problem is that you feeling a little threatened. Let's not talk about us then, let's talk about us now. See my club is bringing in cold hard cash. Now, I, Ron Johnson, is lending you money because you can't even pay your phone bill or even provide for your woman.

D'Wayne: So what if you lent me $\$ 200$, that's the least you could do. They only reason you ain't fat is from all the exercise you get from opening and closing, opening and closing my refrigerator door.

D'Wayne: Tell em something. No, tell me something shorty. Does that light bulb really go out or is that your shadow blocking the light? Huh?

Ron" So now you counting favors? So what you need a little food? Have you some food. Here! Have you some money to go buy it. Take the whole thing.

Ron throws money at D'Wayne

D'Wayne: You ain't gotta go that way.

Ron: Somewhere I got this crazy notion that brothers, we're supposed to carry each other.

D'Wayne: Ron, I have a wife. You breaking my back

Ron: Naw baby, I think that's the chip on your shoulder.

Ron is having a hard time opening his own apartment door and D'Wayne sees and offers help

D'Wayne: Aye, you lose your keep again man.

Ron: Naw, it's just stuck. I got it

D'Wayne: Why don't you let me help you?

Ron: Naw, I said I got it. Your back is broke remember?

D'Wayne: Whatever!

As the first portion of the final episode showcasing D'Wayne and Ron's

relationship, their tumultuous interaction heavily strains their kinship. The financial roles

are reversed from the previous semesters, and now D'Wayne is the one that is facing

financial hardships. Ron is now in a position to provide assistance to D'Wayne, and Ron

gives help without a second thought. This is evident when Ron leaves $\$ 200$ behind for 
D'Wayne after watching bill collectors pressure D'Wayne. Within social exchange theory, the "giver" in the give-and-take interaction has now been replaced by Ron, while the "taker" is now D'Wayne. For example, when D'Wayne is solidifying the concept for his videogame, Ron provides ideas that D'Wayne happily accepts. D'Wayne suggests, "What they need to do is develop a cartridge that teaches grammar." Ron then agrees and gives further explanation of his own ideal contributions: "Yeah, make it fun like baseball. See, the noun can be the batter and the pitcher can be the verb." Both friends have shared their creative ideas that will soon become profitable.

Once D'Wayne creates the profitable video game, Ron is alarmed and frustrated that his best friend failed to provide him with any acknowledgement, either verbally or financially, for assisting with the creation of such a profitable videogame. Ron's desire for compensation is an unstated expectation when initially creating the game, but once he finds out that Kinishewa is interested in purchasing the game, those expectations are explicitly stated. D'Wayne is prideful and selfish to the extent of possibly causing his brotherhood and friendship with Ron to terminate. As the communicative interaction progresses, each person places a level of identity on each other. Ron accuses D'Wayne of no longer acting brotherly, while D'Wayne accuses Ron of acting crazy.

Feeney and Collins (2015) provide information on what they document as the "fortification process" within social support (p. 115). The fortification process recognizes that social support and relationship partners are often available to offer encouragement and positivity to other partners. Furthermore, the supportive partner also acts on the ability to recognize and vocalize the positive capabilities of the opposing relationship partner. D'Wayne simultaneously fulfills and violates this portion of Feeney and 
Collins's (2015) description. For example, D'Wayne violates the scholars' philosophy of social support by listing many of Ron's negative characteristics. Specifically, D'Wayne announces, "I always got finer women than you. I got better grades than you. I graduated before you, I got married before you. I got married to the woman you sweated throughout your whole college six year career." The aforementioned statement is just one of many insults that D'Wayne hurls at Ron, coupled with the verbal notion that he has been figuratively carrying Ron their entire friendship. Overall, the mere mentioning of Ron's shortcomings causes Ron to no longer feel the emotional security of a supportive relationship, causing a rift within the friendship. The idea of emotional and social support from the theory of Feeney and Collins (2015) is applicable to the brotherhood that Ron and D'Wayne share. As both characters mature and face conflict in other areas of their lives and, once they allow the outside frustration to infiltrate their relationship, their emotional and social support is at risk.

\section{Season Six Episode 18, "When One Door Closes"}

On May 8, 1993 NBC aired season six episode 18 of $A$ Different World, titled "When One Door Closes" as a second part to the season finale. Whitley finally announces her pregnancy to her husband. Whitley and D'Wayne host a going away party, but Ron and D'Wayne are still at odds, so Ron is absent from the party.

Whitley and D'Wayne discuss their upcoming move to Japan for D'Wayne to take a job with Kinishewa making $\$ 80,000$ a year

D'Wayne: This isn't about 80 grand a year; it's about going one step further. Whitley: Just remember that Ron's idea helped you make that step D'Wayne.

Freddie (Ron's girlfriend) comes to talk to Ron about attending D'Wayne and Whitley's going away party

Freddie: Would you please stop this silliness and come with me to D'Wayne Whitley's farewell party.

Ron: Rain check baby! 
Freddie: Ron, they're going to leave tomorrow.

Ron: Freddie, he's not my friend.

Freddie: Hunny, he just said that stuff to you because he was angry

Freddie leaves to attend the going away party, while Ron stays home

Initially, D'Wayne's pride and selfishness caused the rift between him and Ron.

At this specific pint, both Ron and D'Wayne are extremely prideful and neither of them

want to apologize or initiate the conversation of compromise and understanding.

D'Wayne is preparing to leave the country for an extended period of time, and his own

best friend, Ron, is not attending the going away celebration. Feeney and Collins (2015)

discuss how a relationship partner takes the steps to re-describe adversity. Ron and

D'Wayne violate this recommendation, because at this specific point in the season finale,

their shared adversity has not be evaluated with any desire to end their conflict over

failed expectations. In other words, another motivation has not emerged that trumps their

current frustration with each other:

D'Wayne and Whitley attend their own farewell party and say their goodbyes to everyone

Whitley: 6 years and I feel like I grew up. I never knew that one place could mean so much to a person. You go outside to that cold ugly world and you have a place to come back where people say we love you and you're alright.

Whitley: D'Wayne, you taught me about love and I'll never forget any of you.

D'Wayne: Some friends couldn't make it. Some that taught me not to take life so seriously. Some people that taught me about brotherhood.

D'Wayne: People like Ron Johnson. I came to Hillman as the only child and now I'm leaving with a whole lot of brothers and sisters. A lot of fathers too. Thank you for being my family.

D'Wayne and Whitley vocalize that their tenure at Hillman College has

transformed their group-based and personal identity. They collectively look back over the personal growth they have experienced in what was once a "different world," that soon became their own version of home. Whitley describes her matured identity through the third frame of the communication theory of identity, relational identity (Jung \& Hecht, 
2004). Whitley's individualized relationship with friends, a romance partner, and mentors caused her to acknowledge the amount of love and understanding that allowed her to grow as a woman at Hillman College. Furthermore, Whitley's collective relationships at Hillman College satisfy the fourth and final frame, the communal frame. This frame examines the totality of identity that is birthed through groups of extended size. Whitley mentions that her six years at Hillman have allowed her to grow; although Whitley does not give extensive details on her growth, a dedicated viewer of the show understands Whitley's growth and the manner in which social support has shaped Whitley's identity into a more mindful individual.

Similarly, the identity negotiation theory's first assumption maintains that membership within a group can create individual identity with specialized meaning to the owner of the identity (Ting Toomey, 2005). Whitley's identity at this specific point in the episode has a special meaning to her. This identity has been shaped over six years with lessons learned and relationships that have improved Whitley's understanding of herself and the world around her. Ting Toomey (2005) goes further and suggests that the absence of emotional security can force a person to recoil away from people with whom they do not have a close bond. Whitley supports this principle by gaining emotional security from the relationships gained over time. The third assumption assumes that the existence of emotional security in identity naturally occurs with groups that are culturally homogenous. Once the students at Hillman College begin to have a shared group culture of being African-American students at an $\mathrm{HBCU}$, they begin to share emotional security. Their pride in Hillman College is evidence of their shared group culture. Whitley affirms this assumption by verbally recognizing her emotional security gained through friends 
and her romantic relationship with D'Wayne. D'Wayne affirms the same assumption as well once he acknowledges that he came to "Hillman as the only child and now I'm leaving with a whole lot of brothers and sisters."

D'Wayne and Whitley are all packed up to leave for Japan when Ron comes rushing into the house

Ron: D'Wayne!

Whitley: I'm going to go wait in the car

Ron: Freddie told me about your toast last night. I should've been there

D'Wayne: I wish you had man. Aye listen, about this idea, I was tripping. I saw all that gold, all that money

D'Wayne: It's your idea, you deserve half that money

Ron: But you put the game together and you presented it to Kinishewa

D'Wayne: But still, you came up with half the idea, I have to send you half the money. It's only fair

Ron: D'Wayne, put it towards little Ron's or little Rhonda's college education fund

Ron: Um, I made this for the baby

Ron hands D'Wayne a baby raddle

D'Wayne: You didn't make this, you brought this man

Ron: Just tell Whitley I made it

D'Wayne: You know it would make me proud (*D'Wayne hold back tears), if you'll be the godfather of my child

Ron: I got your back

Whitley: D'Wayne!

Ron: Aye man, ya'll better jet

D'Wayne: I guess we better jet. Take care of yourself brother

Ron: Take care brother

$$
\text { Ron begins to get emotional }
$$

D'Wayne and Ron hug as Ron cries

Whitley: You be a good boy Ronaldus

Ron: I'll miss you Whitley

D'Wayne: You ready to go baby?

Whitley begins to get emotional as she and D'Wayne

prepares to leave

Whitley: Off to a different world D'Wayne and Whitley leave the home as Ron watches

D'Wayne and Ron both put their pride aside and acknowledge their conflict without placing any blame. D'Wayne becomes understanding and admits that Ron is deserving of financial compensation for his contribution to the videogame bought by 
Kinishewa. Both of these relationship partners connect to their relational identity in order to mend their differences. According to Jung and Hecht (2004), the relational identity is created when an individual considers how others perceive them. In this specific situation, D'Wayne understands that Ron deems D'Wayne to have acted out of greed, pride, and selfishness. Similarly, D’Wayne identifies that he believe that Ron was acting out of greed, selfishness, jealousy and what D'Wayne regarded to be craziness. Once both parties analyzed not only how they treated one another, but also how they viewed each other, they were able to provide a better identity for their collective relational brotherhood. For example, Ron informed his girlfriend, Freddie, that he and D'Wayne were no longer friends. However, when Ron and D'Wayne discuss their conflict, D'Wayne asks Ron to be the godfather of Whitley and D'Wayne's unborn child. After recognizing how their opposing relationship partner was viewing them, D'Wayne and Ron were able to come to a compromise with the understanding that selfishness and pride was not worth the end of their friendship, especially with D'Wayne and Whitley journeying to their own version of "a different world." Ting Toomey's (2005) tenth assumption of the identity negotiation theory provides the understanding that effectively cultivates the production of positive images. In fact, D'Wayne and Ron provide support to Ting Toomey's (2005) tenth assumption once they reevaluate their conflict and decide to move forward with mending their damaged relationship.

\section{Conclusion}

In this chapter, I analyzed several episodes of $A$ Different World in order to identify major themes concerning the communication of relational identity. The four thematic appearances include: frustration, pride, selfishness, and compromise. The 
secondary theme within "compromise" includes the characteristic of "understanding." In other words, for the instances that the characters decide to compromise, those characters collectively and ultimately reach some balance of understanding. Recognizing these themes is important to understand how the characters' relationships grow by means of specific communication principles.

Ron and D'Wayne both come to an understanding that their brotherhood should never be tainted by pride, selfishness, greed, a lack of understanding, or a lost desire to understand. Whitley and D'Wayne see the value in their relationship, no matter the differences in their personalities. D'Wayne and Whitley can acknowledge and admire the value of their relationship and its contribution to both of their identities. With each episode, conflict may have been present, but social support eventually saved the relationships and assisted each person with re-gaining their emotional security in their romantic and platonic relationships.

Overall, three theories help explain the key relationships in A Different World. Specifically, those three theories are the communication theory of identity, social exchange theory, and the identity negotiation theory. These theories acted as a lens and allowed me to interpret each episode with a direct focus on the communicative nature of the relationships and identity of the characters. The next chapter will discuss generalizations from the specific episodes and make overall conclusion. 


\section{CHAPTER V}

\section{DISCUSSION}

This thesis is a thematic analysis of $A$ Different World with a focus on the relationships between Ron, D’Wayne, and Whitley. There were four emergent themes that appeared across the eight episodes that spanned across four seasons. The four themes included pride, selfishness, compromise, and understanding. The inductive nature of the thematic analysis allowed the theoretical framework to be used as a lens to examine the thematic characteristics of the text and communicative interactions.

\section{Simulacrum}

A Different World is a simulacrum, a television show that represents real life. Hillman College, a fictitious HBCU, is full of adult mentors for students and AfricanAmerican studies within the academic curriculum. The series' popularity could well stem from the realistic portrayal of college life, more specifically, the experience of postsecondary African-American students. In addition to providing a sophisticated representation of identity and relational evolution, A Different World also provides Americans with an extended look into the functionality of an HBCU. In many of the campus shots, members of the Divine Nine, historically African-American fraternities and sororities, are easily recognizable in the background; these groups are representation of the historical significance of HBCUs and Greek organizations. Culturally, the series even integrated dialogue about the Underground Railroad and race relations shortly after the Rodney King verdict. 
Debbie Allen was at the forefront of ensuring that the writers were authentically informed about the operations of an HBCU and that viewers gained an educational experience as audience members (Ramos, 2015). Viewers learn that HBCU can incubate greatness, provide students with structure, motivate students to help others along the way, and create discussion regarding issues that are meaningful to the African-American community.

While some students at an HBCU may have similarities through their racial background, their life experiences may be totally different. Thus, attending an HBCU allows students to become well informed about the cultural experiences of other students that may derive from differing backgrounds. College can be a different world, and relationships can be the main vehicle to assist in the journey that strives to enhance students on various levels, including: professional, personal, academic, emotional, and mental. A Different World explored these characteristics in a creative way that cemented the show's legacy and popularity.

\section{Relational Themes}

Many of the episodes contained plots that focused on the initial pride of one or more of the characters. For example, in the course of the romantic courtship of D'Wayne and Whitley, there were a multitude of encounters when both of them allowed their pride to cloud their better judgment. 
Pride, Frustration, and Selfishness. This pride had a negative effect on their romantic rapport and at one point, almost ended their relationship completely. Comparatively, selfishness and frustration almost always followed the presence of pride. Whitley was notorious for her recurring selfishness when interacting with others. Whitley's identity was eventually shaped to have a wider set of knowledge on how to be more thoughtful. Similarly, Ron and D'Wayne encountered pride in their friendship, especially during their times of communicative conflict. Their pride interfered with their ability to verbalize their feelings with the absence of insults and misunderstandings. Ron continuously labeled D'Wayne as frugal and uptight, while D'Wayne labeled Ron as a frivolous spender with unrealistic music dreams. There were points when D'Wayne had too much pride and allowed time to pass before he rightfully apologized to Ron. At one point, D’Wayne used Ron's idea to create a lucrative and financially profitable video game. However, D’Wayne is appalled and offended when Ron asks for proper financial compensation. D’Wayne's pride grew and almost ended his friendship with Ron, until D'Wayne lowered his pride and admitted his own wrongdoing. The presence of pride was also available in an additional sense of school pride. Each character took pride in attending an HBCU that promoted Black excellence and life-long relationships.

Compromise and Understanding. For reasons of growth and maturation, compromise and understanding were constantly present, even down to the final episode of the series. Extreme conflict caused a break up between Whitley and D'Wayne, but their willingness to compromise and understand were the main characteristics that led to their marriage. Whitley and D'Wayne's marriage episode was a showcase of the power of love between the two, while it also affirmed Ron and D'Wayne's brotherhood. Conflict 
was never strong enough to dismantled D’Wayne and Ron's kinship. As D’Wayne interrupted Whitley and Byron's wedding, Byron's groomsmen attempted to fight D’Wayne. D'Wayne spoke up to profess his own love for Whitley with Ron physically protecting D'Wayne from harm from Byron's friends. The final episode serves as evidence of the strength of the bonds between Whitley and D'Wayne and Ron and D’Wayne.

Each character allows Hillman College to assist in shaping their personal identity and relationships with others. Hillman College acts as a safe haven and serves the students in an academic and personal sense, albeit through providing mentors, environments conducive for flourishing relationships, and teachable moments. Although Hillman College may be fictitious, it is the home of personal and relational growth for D’Wayne, Whitley, and Ron. What initially began as a mere friendship between Ron and D'Wayne soon flourished into a brotherhood that would allow Ron to become the godfather of D'Wayne and Whitley's unborn child. The eventual marriage between D'Wayne and Whitley started out as a figurative game of cat and mouse, especially during the times that Whitley was not initially interested in D'Wayne. As this series progressed, so did the relationships between Ron and D'Wayne as well as Whitley and D'Wayne despite the consistent setback and roadblocks.

\section{Theoretical Utility}

Three communication theories that served as the lens for interpretation of $A$ Different World, there were. Those scholarly theories include the communication theory of identity, identity negotiation theory, and social exchange theory. These three theories were utilized for the studies of intercultural communication within a popular television 
series. Specifically, the communication theory of identity maintained a focus on the method in which characters verbally communicated the identity of their self-concepts. Although the theory was not initially created for the sole purpose of $A$ Different World, its utility allows the theory to remain applicable in such a manner. This theory can be extended to see the impact of larger cultural forces by focusing on cultural entities that have historical meaning to cultural groups, including: HBCUs, PWI, cultural movements, culturally historic organizations, and television shows. The scope of the theory allows the range to include television characters (Jung \& Hecht, 2004); these characters are initially crafted in the mind of a writer, yet they become popular for their memorable moments and personality traits. Soon, these characters embody personality traits that provide identity complexity as well as traits that enhance the public's interest in the characters. This widened scope is an integral part of the ability to cover various communicative interactions. The communication theory of identity also emphasizes the characters' approach to communicating how they believed others viewed them. The utility of this specific theory is not only valuable to intercultural and intergroup communication, but also to a television show that provides the world with an insight to the happenings of African-American students. This is similar to the Northern Exposure study that used the syndicated series to analyze the communal identity of Jewish Americans (Hecht et al., 2002).

The enacted identity of each character of focus is important, mainly because it addresses the expression of personal characteristics (Jung \& Hecht, 2004). Dyadically, the characters express their own self to their relationship partner. Communally, the characters communicate self in a larger group, specifically to other students at Hillman 
College. Culturally, the characters present themselves to the larger the African-American community. This is reflected in the resolution to the relational conflict that is constant in each set of relationships within this overall text. The method in which characters decide to enact and communicate their personal characteristics, can collectively impact their group, community, and cultural relationships.

Comparatively, identity negotiation theory acknowledges that identity can be formulated through various relationships and the characteristics available, including emotional security and cultural similarity. The utility of this theory, similar to the previously discussed theory, allows it to be applicable to the relationships between the characters of the television series. In this specific instance, this theory is valid in nature, because it accurately predicts the relational and identity effect of the presence or absence of emotional security and cultural similarity and indifference. The presence of emotional security and social support allows the relationships to progress in a positive manner that enhanced the relationships. The absence of emotional security and social support almost guarantees that conflict will appear. In addition, this theory has heuristic value and can be readily applied to other popular television shows that portray characters with complex and multi-leveled identities.

Similar to the extension of the communication theory of identity, the identity negotiation theory can showcase the impact of larger cultural forces by also being applied to entities that have cultural sentimental value and involve the identities of those involved. Both the communication theory of identity and identity negotiation theory have an intentional focus on groups, but, as demonstrated in this analysis, they can be extended to include individual relationships. This extension is possible since the individual 
relationships have an eventual impact on the group identity and vice versa. For example, the relationships between Ron, D'Wayne, and Whitley shape the identity of Hillman College to viewers since these are primary characters.

Comparatively, applying social exchange theory to a film demonstrates the flexibility and heuristic value of the theory. Since this theory was not created for the purpose of relationships displayed on television, the theory lacks some acknowledgment of the initial relational confrontation and eventual compromise in most television episodes. The theory has the utility and heuristic value that was extremely useful in the duration of the analysis; however, further research and rhetorical method usage would be a great way to expand the scope. Through my thematic analysis, I discovered that the back-and-forth nature of the characters' relationships frequently included compromise as a characteristic. Xanthopoulou, Demerouti, and Schaufeli (2009) recognize the reciprocity of relationships, but compromise is not included as a factor. This analysis of $A$ Different World found that compromise was present in both the brotherly platonic relationship between Ron and D'Wayne and the romanticism between Whitley and D'Wayne.

\section{Colorism and Racial Identity}

Many of the $A$ Different World characters face their personal racial identity as they simultaneously better understand their own personality characteristics in reference to their collegiate environment. They understand that there is systematic racism within the world outside of Hillman College as it is displayed in the conversations about Rodney King's beating and experiencing racism when the characters visit another college's football game. The series uses the counter-narrative of the critical race theory to provide 
an alternate viewpoint to stories on racism. Solórzano and Yosso (2002) explain that critical race theory strives to problematize and eliminate racism in the form of proper education. This is applicable to A Different World's portrayal of the Rodney King riots. The original national story focused on the African-American looter and rioters, while $A$ Different World spotlighted White looters. This counter-narrative intended to recognize that the looting and rioting was not just synonymous one specific group.

Whitley is the main character of the show, and she is fair-skinned with a family that has abundant financial security. Whitley's level of initial selfishness is really a masking of her classism as a wealthy and fair-skinned African-American. At one point, she found that her family owned slaves during the slavery era. Yet, Ron and D'Wayne were called racial slurs as they visited their rival school's football game. Although the two aforementioned episodes were not included in this thesis, these are incidents that took place and had an impact on the characters' racial identity. In contrast to Whitley's appearance and background, D'Wayne is dark-skinned and comes from a working class family. Ron is portrayed as lighter-skinned, yet he is the "ladies man" and very promiscuous. Colorism is part of A Different World, whether intentional or unintentional by show writers. A friend of Whitley, Kimberly Reese, is dark-skinned and has colorism issues when she once was mistaken for the "Mamie" figure that defamed darker-skinned women. The depiction of colorism is a representation of the remnants of racism and the rank order of African-Americans that is based on skin color and financial status.

Race has an impact on the way in which the characters interact. For example, D'Wayne and Ron have constant confliction in their relationship, but they consistently come back together and reconcile. This indicates the African-American community 
understanding that as a cultural group, we are worth more collectively than individually. Overall, the larger African-American culture is reflected in the relationships, because of Hillman College's atmosphere and the characters' membership within the AfricanAmerican culture.

\section{Impact of Hillman College}

However, Hillman College shielded the characters away from some of the harsh racism and discrimination that took place outside of Hillman College. This form of protection was an opportunity to strengthen their racial identity and also focus on their personal identity and relationships. Smith, Allen, and Danley (2007) discussed how microagressions takes a mental toll on African-American students. These microaggressions can then lead to racial battle fatigue, even though these same students are expected to maintain their personal and academic success. After viewing these individual relationships, an audience learns that as an $\mathrm{HBCU}$, Hillman College was a safe haven for Ron, D'Wayne, and Whitley in a way that a PWI may not have been able to provide such shielding.

Furthermore, the characters were able to use Hillman College's African-American cultural heritage to better shape their own racial identity. The influence of Hillman College is so strong that this institution deserves to be included as an additional character in the relationships of focus. Considering place as a character, while not very common, has been analyzed by other scholars (Beeton, 2010). As previously mentioned, Hillman College protected the characters from outside harsh racism, but guided their relational growth. Although the outside racism is shielded, the normative racism embedded in classism is within the storyline and the overall plot of the series. The characters are 
influenced by the larger culture at Hillman College to remain focused on their academic and professional success, while maintaining relationships with longevity. Hillman College provided the literal environment for the characters' growth. 


\section{CHAPTER VI}

\section{LIMITATIONS AND FUTURE RESEARCH}

Despite the useful findings, this analysis has multiple limitations. For example, my own personal connection to the show serves as a limitation. As previously stated, I am passionate about this television series and the direct correlation and reach it has with college students and the African-American community. When observing the character relationships, these were the same relationships that I admired as a young child. My personal admiration already confirmed that despite the relationships' constant ups and downs, I always viewed them as generally positive in nature because they succeeded regardless of the struggles. My passion for the series also involved me maintaining a parasocial relationship with the characters when watching the show (Schiappa, Allen, \& Gregg, 2007). These personal biases were acknowledged in the early sections of this text.

Subsequently, this text does not include an analysis of all of the show's characters, whether major or minor. There are additional characters that are spotlighted in A Different World, but not included in this thematic analysis. As a limitation, the characters included in the analysis had interactions with those other characters, and there could have been times when those interactions could have provided the characters of focus with identity-shaping communicative feedback. Those characters are worthy of research within theoretical frameworks, including: Jalisa, Freddie Brooks, Mr. Gaines, Kimberley Reese, and Walter. Continuous support was provided through the social encouragement of these secondary characters. These characters also add to many of the 
storylines across the entire series. The larger community and culture has an impact of shaping-power on the individual and relational identity of the characters and their relationships. The individual relationships are key to the overall communal identity at Hillman College and the African-American community.

Correspondingly, I did not include all episodes of the series, nor did I include a wide range of episodes from every single season. Furthermore, with the episodes that I did include, I only focused on the segments that analyzed the interactions related to the relationships of Ron and D'Wayne and Whitley and D'Wayne. Omitting multiple episodes allowed me to narrow the thematic analysis, but also presented the possibility of not including some identity-shaping moments that happened during communicative interactions between my characters of focus and other characters that were not the object of focus. This limitation is qualified to also include my usage of limited and specific episodic interactions.

The relationships are treated as if they purely real-life relationships instead of being recognized as a facet of television. The power of television normally showcases conflict and a follow-up resolution. This serves as a limitation within this study, since the complexity of the characters is meant to interact, but eventually portray a consistent giveand-take nature. In contrast, some relationship facets face extreme conflict and then dismantle the relationships without any reconciliation.

Notwithstanding, future research can use this critically acclaimed television show as the basis for a quantitative study. Participants that are both African-American firstgeneration college students and viewers of $A$ Different World can be surveyed to analyze the impact, if any, on their perception of college before actually attending. This same 
study could strive to determine if $A$ Different World served as inspiration for firstgeneration African-Americans as they matriculate academically. Similarly, this show can be the foundation of another quantitative study that surveys students at HBCUs. This analysis could use scholarly research to determine the personal, professional, and academic impact $A$ Different World had on current and alumni students of HBCUs. If researchers want to personalize these aforementioned studies, qualitative methods such as focus groups and one-on-one interviews can gather more extensive and personal data. If qualitative, these studies would then provide emergent themes to offer a greater explanation of if and how HBCU students relate and identify with A Different World.

Uniquely, the theories of study are great in heuristic value and allow for usage in similar future studies. As previously mentioned, the series acknowledges the Divine Nine, and first-generation college students. Specifically, the communication theory of identity and identity negotiation theory can be applied to the identity of members of the Divine Nine. Traditionally, these students are scholars, student leaders, service-oriented, but they also have to communicate their identity to their fellow classmates, chapter members, and their national organization. Each entity can possibly represent a portion of the student's identity that may differ by level.

Likewise, the communication theory of identity and identity negotiation theory can be used to investigate how HBCU students negotiate and communicate their personal, academic, professional, and racial identities with friends that may attend a PWI. The institutions may have differences in resources, influence, and overall environment for students, thus contributing to their identity. Identity negotiation theory can also examine $\mathrm{HBCU}$ students that are from inner cities with a lower socioeconomic status. 
This study would seek to understand how this specific group of HBCU students convey both identities as a college students and residents of the inner city.

Comparable to the other two theories, social exchange theory has enough value to endure the basis for future research. This theory establishes that relationships are full of implicit and explicit expectations, as well as reciprocity. Platonic and romantic relationships may have varying levels of reciprocity and expectations. Future research can use this theory to discover the intricate similarities and differences between the levels of relationship, simple friendships and romantic relationships. HBCUs are known for their alumni presence, and this was indicated on $A$ Different World. Potential examination can probe mentor-mentee relationships of HBCU students and alumni. Mentors are notorious for being a constant resource and providing guidance to those that may be on a similar journey in life. Quality mentors are giving of their time and not afraid to be frank about their personal failures and lessons learned along the way. Social exchange theory can offer a closer look at the give-and-take nature of mentor-mentee relationships and the accompanying expectations on behalf of both parties.

Since the communicative theories were applicable to A Different World to better understand relationships, it would enhance the heuristic value to include popular television series and movies that have African-American lead characters. The television shows and movies for study should consist of those that have yet to be used for scholarly research, yet they have sentimental value to its African-American viewers. There are current and older series that focus on relationships and identity, including: Scandal, How to Get Away With Murder, Being Mary Jane, Power, The Game, Half and Half, The Wire, The Wayans Brothers, and Martin. Similarly, there also movies with a similar 
focus, including Love and Basketball, Brown Sugar, Straight Outta Compton, War Room, and Best Man. Upcoming exploration can examine the characters' relationships and their identity as the movie or television show progresses. Many of these pieces portray characters that have a multi-layered identity that consistently evolves. Movies and series with African-American lead characters merit academic focus to provide a greater understanding of the characters, which could in turn offer a better comprehension of its significance to its audience. A dissection of the colorism in this show would make a concrete research opportunity within various academic fields, including psychology, communication, higher education, African-American studies, and sociology. Similarly, the characters also moved closer to understanding their own gender and biological sexual identities. Ron made it known that he was consummating his relationships with women on campus, while D'Wayne was more conservative in nature. Ron and D'Wayne expressed their male identity in very different ways.

Lastly, a rhetorical study could compare and contrast the depiction of HBCUs in A Different World to actual HBCUs. The show tackles Greek life, residence hall stepping clubs, consistent mentors, and African-American studies embedded into curriculum. Scholars can use their evidence of actual HBCUs and equate those characteristics to the fictitious Hillman College. If the hypothetical study found Hillman College to be an accurate general representation of HBCUs, this could then provide a heightened level of credibility for A Different World and its writers.

\section{Conclusion}

Overall, A Different World is of cultural and social importance to the AfricanAmerican community as it unapologetically addressed relevant social issues. Even after 
the series' end in 1993, it is still often mentioned on social media and maintains a strong cultural relevance (Obell, 2014). The characters are complex in nature, which is a compliment to the directors, producers, and writers on the show. D'Wayne and Whitley maintain their love even as they travel off to Japan; their own version of "a different world." Ron and D'Wayne embody brotherhood that they both promise will last, even in the distance. Collectively, each of the characters' identity is cultivated and enhanced through their relationships and social support. As their relationships grow, the characters simultaneously experience intrinsic growth. Most of the conflicts were due to the lack of social support. Whitley begins the series as an entitled young woman that is only concerned with her own way of life, with very little regard for the circumstances of others. In contrast, Ron enters Hillman College as a pseudo-ladies' man. Eventually, Ron gains his confidence and attracts as many women as he can handle. In his first year at Hillman College, D'Wayne is known as a geek that does not get the women for whom he has a romantic interest.

Throughout their years and experiences at Hillman College, each of the aforementioned characters matures and enters adulthood with better characteristics than those with which they started. Hillman College is the sole provider of the environment that is conducive to the characters' personal and relational identity. Their collective social support was instrumental in each of the character's understanding that their conflicts did not impede on their care and love for each other. Their intrinsic growth is united with the growth of their coupled relationships. What is striking -- despite the selfishness, pride, and frustration -- compromise and understanding outweigh any negative characteristics. $A$ Different World is a television show that mirrors the culture of HBCUs while also 
highlighting the importance of maintaining positive relationships in a world that may be different from where we originally find ourselves. 


\section{REFERENCES}

Allen, W. (1992). The color of success: African-American college student outcomes at predominantly White and historically Black public colleges and universities. Harvard Educational Review, 62, 26-45.

Arnett, A. A. (2014). State of HBCUs. Diverse Issues in Higher Education, 31, 18.

Associated Press. (1988). NBC wins in ratings for season. The New York Times. http://www.nytimes.com/1988/04/21/arts/nbc-wins-in-ratings-for-season.html. Retrieved October 23, 2015.

Beeton, S. (2010). Landscapes as characters: Film, tourism and a sense of place. Metro, issue $166,114-118$.

Black (African-American) History Month: February 2012. https://www.census.gov/newsroom/releases/archives/facts_for_features_special_ editions/cb12-ff01.html. Retrieved August 20, 2015.

Brenner, J., \& Smith, A. (2013). Pew Research Center. 72\% of online adults are social networking site users. Retrieved from http://www.pewinternet.org/2013/08/05/72-of-online-adults-are-socialnetworking-site-users/.

Carron, A. A. (2013). I tweet therefore I am: An interview study of identity development and portrayal of Twitter users utilizing the communication theory of identity (Unpublished master's thesis). Retrieved from http://ir.library.oregonstate.edu/xmlui/handle/1957/42702. 
Carter, J. (2011). Huffington Post. A Different World minimizes a different age for HBCUs. Retrieved from http://www.huffingtonpost.com/jarrett-1-carter/adifferent-world-minimiz_b_915035.html.

Collins, J. \& Friedman, M. (Writer), \& Debbie Allen (Director), (1992). Interior Desecration (Television series episode). Tom Werner (Executive Producer), $A$ Different World. University City, CA: Universal Studios.

Collins, J. \& Friedman, M. (Writer), \& Kadeem Hardison (Director), (1992). Occupational Hazards (Television series episode). Tom Werner (Executive Producer), A Different World. University City, CA: Universal Studios.

Eyal, K., \& Cohen, J. (2006). When good "Friends" say goodbye: A Parasocial breakup study. Journal of Broadcasting \& Electronic Media, 50, 502-523.

Fales, S. (Writer), \& Debbie Allen (Director), (1989). The heat is on (Television series episode). Tom Werner (Executive Producer), A Different World. University City, CA: Universal Studios.

Fales, S. (Writer), \& Debbie Allen (Director), (1991). Do you take this woman? (Television series episode). Tom Werner (Executive Producer), A Different World. University City, CA: Universal Studios.

Fales, S. (Writer), \& Debbie Allen (Director), (1993). When one door closes (Television series episode). Tom Werner (Executive Producer), A Different World. University City, CA: Universal Studios.

Feeney, B. C., \& Collins, N. L., (2015). A new look at social support: a theoretical perspective on thriving through relationships. Personality and Social Review, 19, 113-146. 
Fries-Britt, S., \& Turner, B. (2002). Uneven stories: Successful Black collegians at a Black and White campus. The Review of Higher Education. 25, 315-330.

Fuller, L. K. (1992). The Cosby Show: Audiences, impact, and implications. Westport, CT.: Greenwood Press.

Fürsich, E. (2009). In defense of textual analysis: Restoring a challenged method for journalism and media studies. Journalism Studies, 10, 238-252.

Gasman, M., \& Tudico, C. L. (Eds.). (2008). Historically Black colleges and universities: Triumphs, troubles, and taboos. New York, NY: Palgrave Macmillan.

Gasman, M. \& Bowman III, N. (2011). How to paint a better portrait of HBCUs. AAUP.Org. Retrieved from http://www.aaup.org/article/how-paint-better-portraithbcus\#.Vf94xd7U7zI.

Genovese, J. (2015). Sports television reporters and the negotiation of fragmented professional identities. Communication, Culture \& Critique, 8, 55-72.

Gewertz, K. (2005). Decades of dedication. Harvard Gazette. Retrieved from http://news.harvard.edu/gazette/2005/02.10/05-poussaint.html.

Gray, H. (2000). The politics of representations in network television. In H. Newcomb (Ed.), Television: The critical view (6 ${ }^{\text {th }}$ ed., pp. 282-305). New York: Oxford University Press

Guest, G., MacQueen, K. M., \& Namey, E. E. (2011). Applied thematic analysis. Thousand Oaks, CA: Sage.

Guo, J. (2015). Washington Post. What people don't get about 'Black Twitter.' Retrieved from 
http://www.washingtonpost.com/news/wonkblog/wp/2015/10/22/why-it-can-beoffensive-to-use-the-term-black-twitter/.

Hampton, H. (1989). The New York Times. "The camera lens as a two-edged sword." Retrieved from http://www.nytimes.com/1989/01/15/arts/tv-view-the-cameralens-as-two-edged-sword.html? pagewanted=all.

Harris, M. (1991). Entertainment Weekly. The evolution of "A Different World." Retrieved from http://www.ew.com/article/1991/04/12/evolution-different-world. Hecht, M. L., Faulkner, S. L., Meyer, C. R., Niles, T. A., Golden, D., \& Cutler, M. (2002). Looking through Northern Exposure at Jewish American identity and the communication theory of identity. Journal of Communication, 52, 852-869.

JET (1992, April). Debbie Allen tells why ‘A Different World' is rated tops among Black TV viewers. JET, 82, 58-59.

Joffe, H. (2011). Thematic analysis. In D. Harper \& A. Thompson (Eds.), Qualitative research methods in mental health and psychotherapy: A guide for students and practitioners (pp. 209-223). Chichester: John Wiley \& Sons.

Joffe, H., \& Yardley, L. (2004). Content and Thematic Analysis. In David Marks and Lucy Yardley (Eds.), Research methods for clinical and health psychology, (pp. 56-68). London: SAGE.

Jung, E., \& Hecht, M. L. (2004). Elaborating the Communication Theory of Identity: Identity gaps and communication outcomes. Communication Quarterly, 52, 265283.

Hecht, M. L. (1993). 2002--a research odyssey: Toward the development of a communication theory of identity. Communication Monographs, 60, 76-82. 
Griffin, C., \& Hill, G. (1986). In our living rooms for 20 years. In G. H. Carson (Ed.), Ebony Images: Black Americans and Televisions (pp. 97-106). Carson, Calif:: Daystar Pub. Co.

Holmes, S. L., Ebbers, L. H., Robinson, D. C., \& Mugenda, A. G. (2000). Validating African American students at predominantly White institutions. Journal of College Student Retention: Research, Theory \& Practice, 2, 41-58.

Katzman, C. (2009). Halftime Mag. The art and technique of HBCU. Retrieved from http://www.halftimemag.com/features/the-art-and-technique-ofhbcu.html.

Kelley, V. A. (1995). Revealing the universal through the specific in "A Different World": An Interpretive approach to a television depiction of African American culture and communication patterns. University of Kansas, Department of Communication. (Doctoral dissertation).

Kennedy, K. (Writer), \& David Blackwell (Director), (1993). When one door closes (Television series episode). Tom Werner (Executive Producer), A Different World. University City, CA: Universal Studios.

Kovalchik, K. (2015). Mental Floss. 14 Things you might not know about 'A Different World.' Retrieved from http://mentalfloss.com/article/62212/14-things-youmight-not-know-about-different-world.

Lee, Y.D. (Writer), \& Debbie Allen (Director), (1991). To tell the truth (Television series episode). Tom Werner (Executive Producer), A Different World. University City, CA: Universal Studios.

Lee, Y.D. (Writer), \& Debbie Allen (Director), (1992). Save the best for last (Television 
series episode). Tom Werner (Executive Producer), A Different World. University City, CA: Universal Studios.

Lee, Y.D. (Writer), \& Rob Schiller (Director), (1990). Love thy neighbor (Television series episode). Tom Werner (Executive Producer), A Different World. University City, CA: Universal Studios.

LeMelle, T. J. (2002). The HBCU: Yesterday, today and tomorrow. Education, 123, 190.

Maslin, J. (1988). New York Times. Movie Review- School Daze (1988)- Film: 'School Daze.” Retrieved from http://www.nytimes.com/movie/review?res=940DE5DD1639F931A25751C0A96 E948260.

Matabane, P.W., \& Merritt, B.D., (2014). Media use, gender, and African American college attendance: The Cosby effect, Howard Journal of Communications, 25, $452-471$.

McDonald, S. (2014). The Washington Post. Black Twitter: A virtual community ready to hashtag out a response to cultural issues. Retrieved from https://www.washingtonpost.com/lifestyle/style/black-twitter-a-virtualcommunity-ready-to-hashtag-out-a-response-to-culturalissues/2014/01/20/41ddacf6- 7ec5-11e3-9556-4a4bf7bcbd84_story.html.

Miller, G.H. (Writer), \& Peter Werner (Director), (1992). Just another four-letter word (Television series episode). Tom Werner (Executive Producer), A Different World. University City, CA: Universal Studios.

Nettles, M. T., \& Perna, L. W. (1997). The African American education data book: Higher and adult education (Vol. 1). Frederick d Patterson Research inst. 
Nuru, A. K. (2014). Between layers: Understanding the communicative negotiation of conflicting identities by transgender individuals. Communication Studies, 65, 281297.

Obell, Slyvia (2014). Essence Magazine, Debbie Allen still in talks about A Different World reboot. Retrieved from http://www.essence.com/2014/04/28/debbie-allenstill-talks-about-different-world-reboot.

Oprah (2014). Where are they now: Debbie Allen on the social impact of $A$ Different World. Retrieved from http://www.oprah.com/own-where-are-they-now/DebbieAllen-on-the- Social-Impact-of-A-Different-World-Video.

Orbe, M. P. (2004). Negotiating multiple identities within multiple frames: an analysis of first-generation college students. Communication Education, 53, 131-149.

Parrott-Sheffer, A. (2008). Not a laughing matter: The portrayals of Black colleges on television. Historically Black colleges and universities: Triumphs, troubles, and taboos, 207-222.

Pehlke II, T. A., Hennon, C. B., Radina, M. E., \& Kuvalanka, K. A. (2009). Does father still know best? An inductive thematic analysis of popular TV sitcoms. Fathering: A Journal of Theory, Research, and Practice about Men as Fathers, 7.114-139.

Personal communication, Joseph Zompetti, August 11, 2015.

Pierson, E., Coleman, R. M., Cavalcante, A., Warner, K. J., Acham, C., Heitner, D., \& Havens, T. (2013). Watching while Black: Centering the television of black audiences (pp. 19-63). B. E. Smith-Shomade (Ed.). New Brunswick: Rutgers University Press.

Ramos, Dino-Ray (2015). ET Online. Binge-watching A Different World: 17 Things you 
totally forgot about this guilt-free Cosby Show spin-off. Retrieved from http://www.etonline.com/news/163731_17_things_you_forgot_about_a_different -world/.

Schiappa, E., Allen, M., \& Gregg, P. B. (2007). Parasocial relationships and television: A meta-analysis of the effects. Mass media effects research: Advances through meta-analysis, 301-314.

Simpson, J. A. (1987). The dissolution of romantic relationships: Factors involved in relationship stability and emotional distress. Journal of Personality and Social Psychology, 53, 683- 692.

Smith, A., \& Raine, L. (2010). Pew Research Center. 8\% of online Americans use Twitter. Retrieved from http://www.pewinternet.org/2010/12/09/8-of-onlineamericans-use-twitter/.

Smith, W. A., Allen, W. R., \& Danley, L. L. (2007). “Assume the Position... You Fit the Description" psychosocial experiences and racial battle fatigue among African American male college students. American Behavioral Scientist, 51, 551-578.

Smith, S. (2013). And Still More Drama!: A Comparison of the portrayals of AfricanAmerican women and African-American men on BET's College Hill. Western Journal of Black Studies, 37, 39.

Solórzano, D.G., and T.J. Yosso (2002). Critical race methodology: Counter-storytelling as an analytical framework for education research. Qualitative Inquiry, 8, 23-44.

Stark, J., \& Alexander, M. (1988). People. It's a different world for dancer and choreographer Debbie Allen: She's moved to prime-time directing. Retrieved from http://www.people.com/people/archive/article/0,,20100468,00.html. 
Stroud, Q. (2014). Black colleges, media, and power of storytelling. Opportunities and Challenges at Historically Black Colleges and Universities, 253.

Taylor, D. (2012). Essence. Exclusive: Jasmine Guy \& Kadeem Hardison on A Different World 25 years later. Retrieved from http://www.essence.com/2012/09/20/exclusive-jasmine-guy-kadeem-hardisondifferent-world-25-years-later.

Ting-Toomey, S. (2005). Identity negotiation theory: Crossing cultural boundaries. Theorizing about intercultural communication, 211-233.

Van Camp, D., Barden, J., Sloan, L. R., \& Clarke, R. P. (2009). Choosing an HBCU: An opportunity to pursue racial self-development. The Journal of Negro Education, 78, 457- 468 .

Xanthopoulou, D., Bakker, A. B., Demerouti, E., \& Schaufeli, W. B. (2009). Reciprocal relationships between job resources, personal resources, and work engagement. Journal of Vocational behavior, 74, 235-244. 


\section{APPENDIX}

\section{TRANSCRIBED EPISODES}

\section{Season 3 Episode 2 "The Heat Is On"}

D'Wayne: What are you doing?

Ron: I'm keeping my silk dry.

D'Wayne: Do me favor, show me how you use this stuff.

Ron: Brother, either I did not hear you correctly, or you need a class in remedial hygiene pronto.

D'Wayne: Huh, please, I'm trying to prove a point. Tear off some paper.

Ron: You know I wonder about you sometimes. May be that last roach bomb, it probably killed off some of your brain cells.

D'Wayne: You're the reason we go through 3 of these a week, you use too much.

Ron: This is a normal amount.

D'Wayne: They wrapped King Tut in less than that.

Ron: Well hey, that's the way we do it in my family.

D'Wayne: Well, mummify your hand when you go home at Christmas.

Ron: Alright alright, c'mon we're going to be late for the concert.

D'Wayne: Concert? I thought we were taking these girls to a movie

Ron: We were, but with my juice and \$76, we are now taking them to see Branford

Marsalis at the Palace. No applause, just \$38 for your tickets

D'Wayne: Ron, I don't have the money

Ron: Oh C'Mon mister big summer corporate intern. Start spreading some of that Kinishewa cash.

D'Wayne: I have expenses I didn't have last year. I have to pay for utilities. I have to pay for bus fare. I got to buy you toilet paper. Besides I have to help my cousin Rosy buy her wedding dress.

Ron: What's \$30?

D'Wayne: That's three yard of fabric and Rosy gon need all the fabric she can get

Ron: Is it my fault your cousin is a heifer?

D'Wayne: That's not the point and don't you ever call anyone in my family a heifer again.

Ron" I'm sorry I'm sorry.

D'Wayne: I got 20 bucks, it's my last 20. I'll give the rest next week.

Ron: Oh save it, you're going to need it for the cappuccinos afterwards.

D'Wayne: 20 bucks? Where are we going for cappuccinos? Rome?

D'Wayne turns the apartment lights off.

Ron: Naw, leave them on, otherwise we're going to come back for the great roach stampede.

D'Wayne: We killed off all the roaches. 
Ron: Oh no, the mutants survived. And you know how ladies feel about roaches... "Oh roaches woo roaches."

D'Wayne: Hey, I just spent my entire morning in the financial aid office, which should be retitled the office of "We don't care, that's your problem."

Ron: They say they didn't have your check?

D'Wayne: And when I asked the lady what the hold up was, she said, "Excuse me honey child, but your name begins with a "W" and we have a back log.

D'Wayne: I said, what am I supposed to do? She said, "oh baby get another name and leave me alone. Next!"

Ron" I have news that will you cheer up and cool you down. Air conditioners on sale at Radio Robs.

D'Wayne: Ron, it's going to be hot for another two weeks. That's a waste of money. Ron: If we had air conditioner the other night, maybe the ladies would have stuck to us instead of the furniture."

D'Wayne: Partner, tonight we declare war on heat. Rocky road ice cream and our new deluxe compact fan. It's a little rusty, but... Hey, how'd it get so cool in here?

Ron: Because the war on heat has been won, you can take the deluxe fan back to the trash ban you found it in.

D'Wayne: Ron, tell me they were giving these away at the bank instead of calendars.

Ron: Of course not. It was on sale at Radio Robs and brother it's your brand, Kinishewa.

D'Wayne: Couldn't you think to talk to me before shelling out this cash?

Ron: Did you think to talk to me before you brought that rust-blowing machine?

D'Wayne: But that was only three bucks.

Ron: I hope so.

D'Wayne: Ron, for two weeks we could have lived with it. But now, we're out a hundred dollars?

Ron: Actually, it was \$176. 90.

D'Wayne: You're unbelievable, I live on a budget.

Ron: There you go beating that budget bongo again.

D'Wayne: Oh, That's good. That's good from Richy Rich

Ron: Richy Rich? Well, I'd rather be Richy Rich than mister tater tot, toilet paper

tabulator

D'Wayne: Are you calling me cheap?

Ron: Yeah, matter of fact, I can see it now. You'll be CEO of Kinishewa Electronics. Just like Howard Hughes, too cheap to get a dollar hair cut.

Ron: You'll have dreadlocks down to ya toes boy. The only money you'll spend is on a flea bomb, and then you'll wonder why you don't' have a woman.

D'Wayne: Well, I wouldn't set a flea bomb off in your house, it would kill your wife

Ron: I'm not going to look at your rusty scrooge behind for another minute. If you don't like the air condition, you get out.

D'Wayne: Well, you know what, I'm gone

Ron: Good, but you forgot something! *Throws rusty fan out the door towards D'Wayne

In the next scene, Ron fiddles with the air conditioner

Ron: Hey, what you do to my air conditioner? 
D'Wayne: I didn't touch it

Ron: I only brought a Kinishewa because of you. Next time, I'm going to Sears.

Ron: It's a fire! Call 911. Quick. Where's the phone, we need the fire department. D'Wayne unplugs the smoking air conditioner.

Ron: Good thinking

D'Wayne: Thank you.

Ron: I still say you acted like a jackass.

D'Wayne: No no no, you acted like a jackass.

D'Wayne: You want some ice cream?

Ron: I'll get some spoons.

D'Wayne: Fine

Ron: Good

D'Wayne: Remember to stay on your side of the carton.

Ron: But you got all the marshmallows

D'Wayne: Well then switch sides.

Ron: Well now you got all the almonds. 


\section{Season 4 Episode 10 "Love Thy Neighbor"}

Whitley: I'm talking about for my marketing project? I can't do it all by myself.

D'Wayne: Well, that's why God created F's.

Whitley: D'Wayne, you used to take Professor McClaren's marketing class didn't you?

D'Wayne: Yes

Whitley: Then surely you must know somebody that knows something about marketing.

D’Wayne: Yeah, Professor McClaren.

Whitley: D'Wayne would it be that much of an imposition?

D'Wayne: Yes Whitley.

Whitley: I'm desperate, won't you help me?

D’Wayne: You know I will.... For $\$ 6.50$ an hour

Comes back in the next scene

Whitley: D'Wayne, I got an A on my assignment. To show my appreciation, I'd like to take you to dinner. You know, it wouldn't be anything fancy, funds are limited, but it's dinner.

D'Wayne: Um, no thanks Whitley. I had a uh big lunch today. Maybe some other time. Whitley: Ok, just let me know when and thank you for the help.

*Whitley leaves and Ron and D'Wayne began talking

D'Wayne: Dude, that woman is conniving, manipulative, canifrvous, omnivorous, ubiquitous

Ron: Enough of this, you're telling the wrong person

D'Wayne: Of course I am. I just don't feel like dealing with her.

Ron: D'Wayne, notwithstanding her evilness, Whitley really digs you.

D'Wayne: This is true

Ron: You dig her, but if she keeps coming up empty, she's sure to find another well. And that's going to live you high and dry and ready to cry. Bye!

D'Wayne: Whitley open the door!

Whitley: I'm too ugly to let you in.

D'Wayne: Alright cool, I'm leaving and won't be back.

Whitley: No!

Whitley opens the door to find D'Wayne still there.

D'Wayne: I knew you'd see it my way.

Whitley: Do come in.

D'Wayne: Don't mind if I do

Whitley: Just give me a minute to get out of this funk wear.

D'Wayne: No no no, you're not going anywhere. I'm ready to eat

Whitley: I didn't expect you this evening.

D'Wayne: Well, I was passing through the gourmet parfait and it made me think of you

Whitley: What are you gawking at?

D'Wayne: Those green splotches on your face. Oh no, Miss perfect have on pimple cream and a jheri curl

Whitley: This is not a jheri cap; it's a polytechnic moisturizer control cap

D’Wayne: A who? A who? A who? 
Whitley: I suppose you think this is very funny D'Wayne.

D'Wayne; But tonight I didn't come here for a laugh, I came here to get the record

straight.

Whitley: Time to put the birdy in the oven

D'Wayne: Yeah, that's something you're good at

Whitley: Cooking?

D'Wayne: No, avoiding.

Whitley: Would you like something to drink? Pop or juice?

D'Wayne: Whitley there you go.

Whitley: Ok D'Wayne. What am I avoiding?

D'Wayne: Why didn't you answer any of my letters this summer?

Whitley: This summer?

D'Wayne: Yes, the three months in the year when it's hot.

D'Wayne: I wrote you five letters. I wrote you five long letters.

Whitley: I read them all D'Wayne, carefully and lovingly.

D'Wayne: So carefully and lovingly that you couldn't write me a two line postcard back?

Whitley: Wanna know the truth?

D'Wayne: Yeah, where there's a fresh approach.

Whitley: I did write you back, but I didn't mail the letters, because I wanted you to miss me more.

D'Wayne: You're sick.

Whitley: I was sick and I was playing games, but all that's changed now.

D'Wayne: Not since I've last checked.

Whitley: What are you talking about?

D'Wayne: I'm talking about kissing my best friend in my face

Whitley: Oh that.

D'Wayne: Yes that. Playing me and Ron off each other. That's deep Whitley

Whitley: I thought I had to play games to get you D'Wayne. But I swore I would never

play them once I had you

D’Wayne: No no, you don't have me yet.

\section{D'Wayne and Whitley sit down for dinner}

D’Wayne: *makes a throat clearing noise

Whitley: I feel much better now.

D'Wayne: Well now that you are properly groomed, can we eat?

Whitley: I can't believe that we're sitting here, together. Friends

D'Wayne: Neither can I.

Whitley: We've overcome some many obstacles D'Wayne. My silly reservations about you, your silly relationship.

D'Wayne: Stop, silly reservations? What are you talking about?

Whitley: You know.

D'Wayne: No I don't.

Whitley: The difference in our backgrounds

D'Wayne: What? I'm from New York and you're from Virginia? 
Whitley: D'Wayne, when I met you, you were a geeky-lectris freshman with no culture, no class, and no car.

D'Wayne: And you were a snotty wanna-be diva working on everybody's last nerves,

But I got over that. I saw past that.

Whitley: You had less of a journey to take.

D'Wayne: Woah, hunny don't flatter yourself.

Whitley: D'Wayne, you just weren't my prince charming.

D'Wayne: Then, what am I doing here?

Whitley: I've lowered my standards. *laughs,

Whitley: D'Wayne, you really have changed.

D'Wayne: Get out of here. I think the big change you saw in me was Kinu.

Whitley: That is not true.

D'Wayne: Then tell me what's true,

Whitley: I realized I didn't need a prince. I need a man who wants me for me

D'Wayne: I'm not going to be that man if I can't count on you and trust you.

Whitley: You can.

D'Wayne: You can't just say it Whitley, you have to mean it.

Whitley: I do mean it. You're always there for me D'Wayne. I want to be there for you.

Whitley: Just like the song says, "Got to be thereeee, be there in the morning."

D’Wayne: Ok Ok. Easy.

Whitley: I guess I should just come out and say it.

D'Wayne: Say what?

Whitley: I love you.

Whitley and D'Wayne later cuddle on the fire escape.

Whitley: I'm just waiting for a pigeon to descend upon us and interrupt us this time

D'Wayne: There aren't going to be anymore interruptions

Whitley: One more things. These are for you, addressed to Japan

D'Wayne: Probably took you all semester to write these.

Whitley: I told you I wrote them this semester.

D'Wayne: I know, I know. I can't wait to read them

Whitley: Well you have to.

Whitley goes in for a kiss.

D'Wayne: Woah Woah Woah, on more thing..... I love you too.

Whitley and D'Wayne kiss. 


\section{Season 5 Episode 9 "To Tell the Truth"}

Whitley: You're late.

D'Wayne: Well hello to you too. Hey baby, you look good. Maybe a little too good for a family student gathering.

Whitley: I had to wear this lovely ensemble somewhere, you only take me to Burger Hut. D'Wayne: Wow. Is it nag time already Whitley?

Whitley: I'm sorry D'Wayne. But our parents will be here on Friday. Look at this! I'm sorry. I'm just not myself.

D'Wayne: Oh yes you are. It's ok though baby. Everything's going to be ok. Just relax.

Whitley: Yes, everything will be just fine

D'Wayne: Yeah, yeah

Whitley: We're going to go out

D’Wayne: Easy baby, easy

Whitley: We're just going to go out and have a good time. You're not going to wear those dungarees are you? Mama hates dungarees. Please don't wear them around her.

Whitley and D'Wayne attend a dinner and Whitley interrupts as D'Wayne is sitting around and conversing with his colleagues

Whitley: *pats D'Wayne on the thigh as a cue to sit aside and talk with her. Excuse me. Whitley: Pookie, I'm ready to go. We have a lot to talk about. When my parents get here, we won't have time to be alone and play footsie.

D'Wayne: Baby, there's going to be plenty of time for that.

Whitley: I am tired of hanging around this parade of pocket protectors

D'Wayne: Oh, wait a minute now. This is no more boring then those artsy fartsy things

you drag me too.

D'Wayne: It's important for me to mingle with other faculty and students. Babe come on. Whitley: You just don't care D'Wayne! You just don't care about your own engagement party.

D'Wayne: What, do you wake up whining?

Whitley: Not when I've been treated right the night before.

D'Wayne pour punch an accidentally spills the punch on Whitley's blouse in the process Whitley: *Screams My blouse! It's ruined for life!

D'Wayne: I'm sorry, I'll buy you a new one.

Whitley: It's not the same D'Wayne. You are not helpful at all. You are totally insensitive to my prenuptial needs.

D’Wayne: Whitley!! Whitley!!

D'Wayne then runs into Lisa, accidentally smashing Lisa's food onto her shirt

D'Wayne: Oh Damn! I'm sorry.

Lisa: It's ok. Really.

D'Wayne: I'll pay for it, I got my wallet.

Lisa: Listen, calm down. It's not necessary. I'm sure it'll come out. Hopefully

D'Wayne talks to Ron about his encounter with Lisa

D'Wayne: Lisa was so mellow, just like me. I like that.

Ron: But how many women have what Whitley has.

D'Wayne: [Lisa] she was a breath of fresh air. We just clicked.

Ron: But you already clicked with Whitley. Besides, what you two have is destiny, like Romeo and Juliet. 
D'Wayne: They both died Ron

Ron: But they died together

D'Wayne: You see, I don't know if I'm ready for together just yet. Marriage is together

for life and Whitley is so damn needy

Ron: And I love a needy woman

D'Wayne: So what do you do when you can't feel her needs huh?

Ron: I ain't never had those problems

D'Wayne: Not those needs. Listen to me. Lisa and I, we sat together and talked for hours. I looked up and next thing you know, I was having fun with this woman. Just fun. You know.

Ron: Think of all the fun you have you with Whitley. She is fine and she cooks, well she's fine. She's the finest sister I ever saw.

D'Wayne: Yeah, I know. And she loves me to death.

Ron: Then what's the problem?

D'Wayne: Is there anything wrong with having friends. You know, a little stimulation.

Coffee maybe

Ron: Brother, don't do it. I don't think I can take it.

D'Wayne: See that's what I'm talking about. You want me to stay in it for you. With

Whitley, it's all about her. What about me?

Ron: If Whitley is on your agenda. Just remember the three D's: darkness, discretion, and deny and commit these alibis to remember. Number nine is a sure winner

D'Wayne: Ron, I'm going to call Lisa up

Ron: Take my discount card to the come as you are motel

D'Wayne: Lisa isn't the kind of girl you take to a motel

Ron: Well then take somebody else

D'Wayne and Lisa are out on a date

D'Wayne: I had a really good time

Lisa: Me too

D'Wayne: You know, my roommate says I should not have gone out with you

Lisa: Well, you do have a girlfriend

D'Wayne: So why are well here?

Lisa: Because I find you attractive and you invited me, remember?

D'Wayne: That's right, I invited you. I'm guilty as charged

Lisa: Listen, there is no rule that says men and women can't be friends. And if women were friendlier, we'd all have better insight to the opposite sex.

D'Wayne: Or maybe just each other

Lisa: Hmm, how would your fiancé feel about that?

D'Wayne: I haven't given that much thought

Lisa: Well maybe you should. I'm sure she's wondering where you are and who you're

with. And why you're with that person.

D'Wayne: She offered to buy me a beeper

Lisa: If I were her, so would I.

Whitley's friend, Kim, walks into the restaurant and spots D'Wayne and Lisa and walks out before being spotted by D'Wayne and Lisa

Kim: I stopped by the Mirage last night. What were you doing there? 
D'Wayne: I was minding my business. She is just a friend

Kim: Well, you know I had to say something right? It's not everyday you see your friend's fiancé holding hands with anything woman. I'm just looking out for Whitley D'Wayne: Well, I can respect that

Kim: So does Whitley know about this friendship?

D'Wayne: She was there the night we met

Kim: I repeat, does she know about this friendship?

D'Wayne: Look Kim, Whitley has been my world for the last year. I have given this relationship my all. I don't know what else to do, I'm tapped out.

Kim: Be honest

D'Wayne: Yeah

Kim: Whitley won't hear that from me.

D'Wayne goes to see Whitley

Whitley: Pookie! I'm so happy to see you. I'm sorry for the way I acted over that $\$ 250$ blouse. I forgive you. Do you forgive me?

D'Wayne: I forgive you.

Whitley: Let's go make up.

D'Wayne: Hold up. We need to talk.

Whitley: Let's talk after we make up.

D’Wayne: We could, but we won't sweetie. Oh gosh. Last nite..

Whitley: I missed you

D’Wayne: I missed you too, but last night...

Whitley: Get a lot of studying done?

D'Wayne: Woah, it's hot in here

D'Wayne: Sweetie, I don't why I'm telling you any one this, because it probably doesn't mean anything, which is why I'm not sure I'm saying it

Whitley: Aww, my Pookie has such problems expressing himself

D'Wayne: Any when you keep cutting me off, it gets no easier. You sit there, sit here

Whitley: Ok, I'm as quiet as a church mouse. Zip up my lips and throw away he key!

Come on! Come on come on come on!

Whitley: I want to know your every inner most thought

D’Wayne: Last night, I went out with another woman

Episode ends with "to be continued" 


\section{Season 5 Episode 10 "Do You Take This Woman"}

Whitley: You went to dinner with another woman?

D'Wayne: Yes, but nothing happened Whitley.

Whitley: So, why you're telling me?

D'Wayne: Because I wanted to be honest with you

Whitley: That is the worst I've heard.

D'Wayne: Bunny that's the truth

Whitley: Don't call me Bunny, and you better not have taken that tramp anywhere better than Micky D's or HoJoes.

D'Wayne: Whitley, she's not a tramp

Whitley: Oh, now you're defending her

D'Wayne: She's a graduate student studying molecular biology

Whitley: You're dumping me for some egghead

D’Wayne: I'm not dumping you Whitley

Whitley: So you're not attracted to her?

D'Wayne: That's not the point

Whitley: Yes it is.

D'Wayne: Whitley! Lately I've been trapped

Whitley: Well, do you want to call this engagement party off? Maybe I should just call Mama right now.

Preparation for the engagement party persists and D'Wayne pulls Whitley aside.

D'Wayne: Forget everything I said earlier

Whitley: Forget?

D'Wayne: There's too many people here right now. I just want the chance to talk to you, we can work it all out.

Whitley walks away.

The next scene showcases the toast \& cheers portion of the engagement

Whitley: D'Wayne?

$$
\text { party }
$$

D’Wayne: Bunny, I don't know what to say.

Whitley: Ok, Um.

Whitley: It's so nice to look out and see all of you here tonight. All of the people that I love and all of the people that love me. And some of those that aren't quite sure how they feel about me. I'd like to thank ya'll for coming tonight, But I'm not going to be getting married.

D'Wayne: Whitley!

Whitley walks off and D'Wayne chases after her

D'Wayne: Whitley, can we talk about this?

Whitley: There's nothing to talk about D'Wayne. There was a decision to be made and you couldn't make it

D'Wayne: But, I still love you. Sometimes this is going way too fast for me, but my

father says that everybody has doubts.

Whitley: Doubts D'Wayne, not dates. I'm not meant for you.

D'Wayne: No, that's not true. Sometimes, you're too much

Whitley: I want to be your one and only D'Wayne, are you ready for that?

*Silence and Whitley takes off her ring and gives it back to D'Wayne 


\section{Season 5 Episode 13 Just Another Four-Letter Word}

D'Wayne: Mr. Johnson, I'd like to introduce you to some friends of mine who have been looking for you the last few months. Take a look at mister phone bill, mister electric bill, and rent

Ron: Look, I paid the phone bill.

D'Wayne: No, you paid the phone bill with a rubber check.

D'Wayne: Now you messing with my credit Ron

Ron: Don't burden me with these petty details. I got to keep the band's morale up till we win the Rockward Records band competition.

Ron; Till then, I'm sort of in the red

D'Wayne: In the red? What happened to the money that your Pops sent you once you got that diploma?

Ron: That paid for the demo that got us into the finals baby!

D'Wayne: You get on the phone and you call that man and you beg for more money boy!

Ron: Let me explain something to you. I win this record competition, I get a recording

contract and we all get paid.

D'Wayne: Ok, let me explain something to you. Mr. Gaines don't get his money, you out of the apartment!

Ron loses the band competition and D'Wayne arrives to the event upset.

D’Wayne: Ron!

Ron: Mi compadre, partner.

D'Wayne: Don't partner me you no rent bill paying, electric bill dodging dofus. I was

sitting at my computer working on my thesis, when you know what happened?

D'Wayne: The lights when out then the power went off. Do you know how much information I lost?

Ron: Well, I never did understand those computers.

D'Wayne: No? Ok, good. I'll tell you how much. I'll tell you how much. I lost enough to kick your free loading butt out, you evicted man!

Ron: Evicted?

D’Wayne: Aye, you want me to spell it for you? E-V-I....

Ron: I know how to spell it.

Ron: You know kicking me out's not going to pay the other half of the rent.

D'Wayne: Aye But it'll make me feel a lot better man,

Ron: Feel better? Oh so you all large like that D'Wayne? Kick me out on the most devastating night of my life? We lost the contest

D'Wayne: Oh, so now I lose any chance at getting my half of the rent from you.

Ron: I'm not down and out for the count. Tomorrow I'm going to send my tape to

Motown, Columbia, Quincy himself.

D'Wayne: Alright, while you're at the post office. See if they got any job openings.

Ron: I've got a job. I'm a musician.

D'Wayne: Aye man, I mean a job that pays. Wake up and smell your empty bank account fool!

Ron: Well, if you were any real kind of friend, you'd carry me a little longer.

D'Wayne: Oh, Aye. I am your friend. I'm going to carry your bags to the curb. That's it. 
Ron plays his drums on campus to get donations to be able to pay his rent and D'Wayne walks up.

D'Wayne takes Ron's donations from the hat set up to hold the donations D'Wayne: Keep playing keep playing.

Ron: So the vultures come to pick at my flesh. Well, I'm not dead yet.

D'Wayne: Hey, I supported you Ron.

Ron: I have more support at a skinhead rally. Friends don't bail out on you at the first sign of trouble

D'Wayne: Aye, wait a minute. Nobody bailed out on you. You bailed out on yourself. I kicked you out because you need it. I just wish I had on my steel toe boots.

Ron: What you don't understand is that I have to make sacrifices for my music.

D’Wayne: Well I don't.

Ron: Music is my dream and dreams keep you alive

D'Wayne: And money keeps you in the house. Get a job

Ron: Then I won't have time for my music

D'Wayne: Yes! You can do that too. T-O-O as in additional to, conjunction with

Ron: Well, I guess I can crawl back to Jalisa. That job pushing a mop for 7.50 an hour

D'Wayne: Well, if you do that, I guess I could dig a little deeper in my heart to come up with some extra money for rent to carry you for another month.

D'Wayne: We'd have to eat beans though. They'd be cold. The gas is off.

Ron: Ah that's beautiful! That's so sweet! Goes to give D'Wayne a hug

D'Wayne playful pushes him away

D'Wayne: Aw no man. Get off of me man. 


\section{Season 5 Episode 25 "Save the Best for Last"}

As Whitley prepares for her wedding to Byron Douglas, D'Wayne's name is mentioned in the conversation with her mother Mrs. Gilbert.

Mrs. Gilbert: Anything must be better than those yahoos, the Waynes

Whitley: Mama, I learned a lot from those yahoos.

Mrs. Gilbert: Really, what? How the other half shouldn't live?

Mrs. Gilbert: Darling, you really should feel very relieved, because you've done much better for yourself. I mean Byron is an entrepreneur, he's a senator, he's a businessman.

Mrs. Gilbert: You are going to make a wonder first lady.

Whitley Aren't you jumping the gun a little bit?

Whitley's Mom, Mrs. Gilbert, surprises Whitley with a bracelet

Whitley: Mama, D'Wayne came to see me last night.

Mrs. Gilbert: Did you pick your garter for today? Do you want the satin and lace, or you want just the plain one?

Whitley: Did you hear me Mama?

Mrs. Gilbert: I do not wish to discuss that lily liver cad that broke my baby's heart and also ruined one of my better dinner parties.

Whitley: The breakup wasn't all his fault mama.

Mrs. Gilbert: Whitley Gilbert, today is your wedding day. There should be only two men on your mind; Byron because you love him and your father because he's paying. Mrs. Gilbert: Now I do not want to hear another word mentioned about that other individual. Is that clear missy?

Whitley: Yes Mama.

Whitley walks down the aisle with Byron Douglas, but D'Wayne interrupts the as minister asks if anyone objects to the wedding

D'Wayne: Will you? Whitley, I love you and if you'll have me, I want you to be my wife!

Byron: What the hell are you doing?

D'Wayne: I'm sorry. Byron, I love her.

Mrs. Gilbert: Die! Just die!

D'Wayne: Will you have me D'Wayne as your lawfully wedded husband? From this day forth to have and to hold? For richer for poorer?

D'Wayne: Baby please! Please!

Whitley: I do!

Whitley: I'm sorry Byron.

Whitley turns to Byron

Whitley runs to D'Wayne and gives him a kiss.

Minister: Is anybody getting married here today?

D'Wayne: Yes, we getting married. I'm D'Wayne.

Minister: By the power invested in me, I now pronounce you... 


\section{Season 6 Episode 3 "Interior Desecration or Sofa for Good"}

Whitley: Have I told you how happy I am with our new life together and our new home?

D'Wayne: Oh baby, I'm happy too. But tell the truth, don't you miss Ron.

Whitley: About as much as I miss your mother.

D'Wayne: Watch it.

Whitley: I do miss our furniture though. When's that boy gon bring it?

D'Wayne: He should be here pretty soon. I told him he won't get paid until it's delivered/ Whitley: Well, I'm going to be late to this conference. I got to go Pookie

D'Wayne: Woah, what's with this name tag? Hello my name is Whitley Gilbert?

Whitley: Whitley Gilbert's my professional name. Everyone knows me as Gilbert.

D'Wayne: Well they'll have to start getting use to you as Wayne, because that who you

are now, right?

Whitley: Whitley Wayne. Doesn't have a wing to it.

D'Wayne: Oh well why don't you just give me back that wedding-wing.

Whitley and D'Wayne sort through their collective belongings as they decide what is to stay in their new home.

Whitley: D'Wayne, does this look better here? Or over here in the dining room?

D'Wayne: Oh baby, you don't really want to hang that wish I was a wall, do you?

Nothing personal. Nothing personal.

Whitley: I'll have you know that it was given to me by an up and coming artist.

D'Wayne: Well, great. Let's up and hang it in the garage.

D’Wayne: Oh my airplane

Ron: That is a thing of beauty.

Whitley: That's a thing of tetanus

D'Wayne: Oh no baby, this airplane is very special to me. I made this when I was a

freshman. It took me all semester to drink this many beers.

Ron: Both of them.

D'Wayne plays with the airplane while making airplane noises.

Whitley: D'Wayne, D'Wayne, I think we need to pair down a bit

D'Wayne: Yeah, I guess we are a little crowded

Whitley: Ok, I'll tag the things we don't need and Ron can get rid of them

Ron: For an additional fee of course.

D’Wayne: Of course.

Whitely tags all of D'Wayne's items.

D'Wayne: Woah Woah Woah, baby what are you doing?

Whitley: A public service

D'Wayne: This couch is very special to me. Sentimental value

Whitley: Your first piece from the Salvation Army?

D'Wayne: In case you forgot, it was the first time that me \& you...

Ron; Hey, I thought the first time that ya'll...

D'Wayne: Oh hey, ok you gotta go, I'll see you later

\section{D'Wayne throws Ron out}

Ron: Alright, well I come and pick up the rest of your stuff a little later. 
D’Wayne: That's cool. Thank you.

D'Wayne: Now baby, wait a minute why do you want to get rid of my loveseat here?

Whitley: Does horrific eye sore mean anything?

Whitley: I just thought that my stuff has seen a little less wear and tear.

D'Wayne: But it's pink. Sweetie I don't think I can live with a pink couch.

Whitley: Can you try?

Whitley give D'Wayne a seductive look

D'Wayne: Oh I think you may be able to convince me a little more.

D'Wayne: A wait a second, hold it. Why is all my stuff tagged for the furniture grave your?

Whitley: Don't be ridiculous D'Wayne. What's mine is yours and what's yours is gone.

D'Wayne: Whitley please, you have to give up something.

Whitley: Ok Pookie, listen to this. How about I take the Wayne name, and then can I

keep some of my stuff?

D'Wayne: You know what? You have a big problem baby. Such a big problem.

Whitley: What's the big problem?

D'Wayne: You have a control problem

Whitley: I'm being negotiable

D'Wayne: All you want to do is control everything.

Ron walks in and interrupts

Ron: Listen man, is it alright if I just bunked on your sofa for a couple nights?

D'Wayne: Yeah man, you can stay with us till you find your own place.

Whitley: Uggh.

D'Wayne: Ugh, he'll stay on my couch

Whitley: It'll be sitting on the curb.

D’Wayne: Says who?

Whitley: Did we not decide that D'Wayne?

D'Wayne: Aye you know what! All bets are off Whitley! All bets are off!

Whitley: Ok fine hunny. I'll wash my hands of the whole thing. You go through

everything, you pick out what you want and I'll just live with it like a good little wife.

D'Wayne: Fine. Ron, get rid of this, get rid of that. And please rid get of this.

D'Wayne: If you have anything to say, you say it. I'm tired of you and your manipulating passive aggressive Marta attitude.

Whitley: Thank you Dr. Freud, I'll take my severe psychological problems elsewhere Whitley storms out of the house.

D'Wayne: You take all of her stuff and you get rid of it. I don't care where it goes, just take off her stuff and get rid of it.

They both calm down and Whitley sneaks some of her belonging back into the

home, instead of putting them in storage.

Whitley: Hi

D'Wayne: Hey bunny, about this move in

Whitley: I hate it when we fight

D'Wayne: I love you

Whitley: I love you too 
D'Wayne: Aye, what's, what's that phone doing here?

Whitley: Hm?

D'Wayne: I thought Ron got rid of this phone this morning.

Whitley: Well, he probably forgot, it's no big deal anyway. We need another working phone in the house.

Whitley: Oh I forgot I have groceries in the car.

D'Wayne: Let your big strong husband go and get them for you.

Whitley: Mandingo, Mandingo!

As D'Wayne heads off to the car, Whitley runs to grab the rest of her

belongings from the apartment storage and tosses D'Wayne's belongings, including his

lamp, out the window and replaces it with her own lamp.

Whitley: Hi!

D'Wayne: What are you doing?

Whitley: Hmm?

D'Wayne: Where's my lamp? This lamp wasn't here before?

Whitley: That lamp's always been there D'Wayne.

D'Wayne: Whitley, this lamp, the phone, and the picture! Where did you stash all this stuff?

Whitley: I can't remember any other lamp.

D'Wayne: Ok! You're lying and you're sneaky. You wanna be petty? From now on, you only use your stuff and I only use mine. That way it'll be separate, but equal

Whitley: That is ridiculous. You are over reacting

D'Wayne: I brought the bed, I get the bedroom, you make other arrangements.

Whitley: So, I brought the toothpaste. Mr Plaqueman

D'Wayne: Well, I brought the toilet paper, so you have to make other arrangements

Whitley sits in brags to her friends about the power she has over D'Wayne

Whitley: You don't understand Kimmy; wait till it happens to you. I have to give up everything. My style, my taste, my name. What is life?

Kim: Your foolish pride!

Whitley: My foolish pride has gotten me plenty. I can play that man [D'Wayne] like lotto. We all know it. He'll come crawling back on his knees any minute. I'll have him marching to my tune.

\section{D'Wayne appears as Whitley is sitting with her friends}

D'Wayne: Whitley, listen to me. I can't, I'm not going to spend another night like last night. Ok. I can live without furniture, I can't live without you, you're my wife. Let's go with this thing out. C'mon. 


\section{Season 6 Episode 12 "Occupational Hazards"}

Whitley: D'Wayne this is the most important interview since I've lost my job. Heresford Auction house is world-renowned. What do you want me to wear to this interview, your boxer shorts?

D'Wayne: That might guarantee you the job baby.

Whitley: Be serious. I need a new outfit

D'Wayne: Stop it Woman, we can't afford it right now

Whitley: You can't expect me to go out on this interview in that same pink polyester

nightmare with the detachable pearls that I've been wearing to every other interview.

That thing is bad luck, it's cursed

D'Wayne: No, it's paid for

D'Wayne prepares to go out of town

D'Wayne: Baby I love you, good luck on the interview; I'm going to call you tomorrow. And don't buy anything. No promise me

Whitley: I promise

D'Wayne: You promise?

Whitley: I promise

D’Wayne: Say it again

Whitley: I promise!

Whitley closes the door and reveals that she had her fingers crossed behind her

back

Whitley uses D'Wayne credit card to buy a new suit for the interview and accidently

spills wine on the suit before she can return the suit

D'Wayne returns home from his business trip and overhears Whitley

making cold calls as a call salesperson

D'Wayne: Hello!

Whitley: D'Wayne, how long have you been standing there?

D'Wayne: Long enough to wonder what the hell you're doing. The place looks different, did you move a lamp or something?

D'Wayne: Where's the sofa Whitley?

Whitley: I didn't get the job and I tried so hard. Poor me

D'Wayne: No no no, poor you nothing. Where's the sofa Whitley?

Whitley: Did I neglect to tell you that I had to sell the sofa for \$200, so now I owe you

five. Go ahead and yell at me

D'Wayne: You, no I'm not going to yell. That would only make you feel better

Whitley: But Pookie, I went behind your back and got your credit card and brought a

$\$ 700$ suit

D’Wayne: \$700! Whitely! \$700!

Whitley: But now I owe you five...

D'Wayne: I'm not going to yell! Move move move!

Whitley: But I'm sorry Pookie! I'm dialing Pookie. I'm going to pay you back every penny

D'Wayne goes into the kitchen and screams when he realizes the refrigerator is

gone

D'Wayne: Whitley, Where is the refrigerator?

Whitley: 80 bucks, we're down to $\$ 420$. 


\section{Season 6 Episode 17 "When One Door Closes"}

D'Wayne is on the phone with bill collectors as Ron is present

Ron: It pains my ears to hear that my favorite coupon couple is struggling, but maybe I could spot you the money. You know I had a great weekend at the club.

D’Wayne: Well thank you partner. I don't need a nickel for a gumball, I need \$200 to pay my phone bill.

Ron gets up and leaves as D'Wayne is still on the phone

D'Wayne: Declined!? Well aye, let me tell you something, you on the phone with the man of the house now dude. Yeah, well, how about I come down there and reach out and touch somebody with my fists. Hello?

D’Wayne: Damn, I hate being broke!

D'Wayne: Thank you for the crumbs Ron!

D'Wayne picks up Ron's plate and notices that Ron purposely left $\$ 200$ underneath the

D’Wayne:\$200 my brother

$$
\text { plate }
$$

Ron and D'Wayne are in the kitchen as D'Wayne is playing a handheld games system

Whitley: I cannot compete with this stupid contraction.

Ron: Whitley, how can this game be stupid when every kid in America wants one.

D'Wayne: What they need to do is develop a cartridge that teaches grammar

Ron: Yeah, make it fun like baseball. See, the noun can be the batter and the pitcher can be the verb.

D'Wayne: And every time you get an answer right, it can be like a homerun

D'Wayne stays up late working on the game programming idea he and Ron discussed

D'Wayne: Babe, what you doing up?

Whitley: I couldn't sleep. What are you working on?

D'Wayne: a computer program that's gonna out kids like Deshawn. I'm calling it

Grammar Boy.

Whitley: Grammar Boy, that's catchy,

D'Wayne: Yeah, well the program itself is complicated, but the main concept itself is to teach grammar as a baseball game. Play it with me.

Whitley: I'm really not in the mood.

D'Wayne: Shut up! Shut up!

D'Wayne: You're the batter standing at the plate. Just like baseball, you don't know what the pitcher is going to throw at you. It could be a fast ball Wooo! Or curve ball.

D'Wayne: In this case an adjective or an adverb. Now every time you swing, you have a change to complete a sentence and make a homerun.

Whitley: I don't understand, you're the genius.

D'Wayne: Well hunny, just know that I'm going to market this and could be our big break someday and maybe even one day our children will be playing Grammar Boy.

D'Wayne and Ron meet up for lunch

D'Wayne: I've been working night and day on the computer program that is going to skyrocket elementary education. I'm talking pure genius Ron and Kinishewa, they want to buy it! 
Ron: Congratulations partner! Ayeee. I always know you'd have your name lit up across computer screens someday.

D'Wayne: No no no, it's bigger than that. Kinishewa is crazy about using baseball to teach grammar. All I have to do is make it through one more meeting with the big wigs. And if it goes well in there. I'm coming out with the fat pockets like Po-Po-po-Ping! Ron: What a minute. You know what this means for us? WE can finally be business partners.

Ron: Me with my high concepts and you with your little scientific methods. This is a million dollar match made in heaven. Oh this is exciting!

D'Wayne: Ron Ron Ron. Hold it Hold it hold it. Business partners?

Ron: Alright. Wayne and Johnson. My motto is no need to be petty when you chingching! About to get paid

D'Wayne: What does my computer program have to do with you?

Ron: The baseball game was my brain child, remember?

D'Wayne: Oh hold on baby, you have to have a brain to have a brain child

Ron: What does that mean? I came up with the whole thing.

D'Wayne: Oh Ron. No offense, but the guy that was watching Ben Franklin fly the kite doesn't get cut into the electricity deal

Ron: Maybe that's because Ben stole Ol' boy's kite. Now let the record show it was my idea

D'Wayne: Ron, the idea came form a simple conversation we had

Ron: NOT THEE IDEA, my idea

D'Wayne: You wouldn't know a good idea if it jumped up and slapped you in the face.

Boy what are you talking? You know what, if it means that much to you, I'll give you

$5 \%$, but I'm going to be able to carry you this time

Ron: When have you carried me?

D'Wayne: Ron, come on. We both know that every time something good happens to me, you get jealous unless you get to tag along. Ok, I'm not going to be able to do it this time baby.

D'Wayne: I been carrying you since me met. Ron, what do you want?

Ron: You think I'm jealous of you?

D'Wayne: You know what? I thin you're crazy. Let's drop it.

Ron: Naw naw naw. It's too late to drop it. Let's put our cards on the table, brother.

D'Wayne: You wanna get real?

Ron: Please do.

D'Wayne: Alright. Well, I always got finer women than you. I got better grades than you. I graduated before you, I got married before you. I got married to the woman you sweated throughout your whole college 6 year career.

D'Wayne: Shall I go on? You want me to go on with this?

Ron: Naw. Let me go on for a while. See, the problem is that you feeling a little threatened.

Ron: Let's not talk about us then, let's talk about us now. See my club is bringing in cold hard cash. Now, I Ron Johnson is lending you money because you can't even pay your phone bill or even provide for your woman. 
D'Wayne: So what if you lent me $\$ 200$, that's the least you could do. They only reason you ain't fat is from all the exercise you get from opening and closing, opening and closing my refrigerator door.

D'Wayne: Tell em something. No, tell me something shorty. Does that light bulb really go out or is that your shadow blocking the light? Huh?

Ron" So now you counting favors? So what you need a little food? Have you some food. Here! Have you some money to go buy it. Take the whole thing.

Ron throws money at D'Wayne

D'Wayne: You ain't gotta go that way.

Ron: Somewhere I got this crazy notion that brothers, we're supposed to carry each other. D'Wayne: Ron, I have a wife. You breaking my back

Ron: Naw baby, I think that's the chip on your shoulder.

Ron is having a hard time opening his own apartment door and D'Wayne see and offers help

D’Wayne: Aye, you lose your keep again man.

Ron: Naw, it's just stuck. I got it

D'Wayne: Why don't you let me help you.

Ron: Naw, I said I got it. Your back is broke remember?

D'Wayne: Whatever! 


\section{Season 6 Episode 18 "When One Door Closes"}

Whitley reveals her pregnancy to D'Wayne. Whitley and Ron discuss

Whitley's pregnancy when D'Wayne walks up without speaking to Ron and Ron walks off to grab Whitley some food, showing D'Wayne and Ron are still upset with each other.

Whitley: That is your best friend

D'Wayne: Whitley please, stay out of it, that's between me and him

Whitley: Oh, I'm sorry. I'm not supposed to talk about this subject either. Forgive me oh husband of mine oh king.

D'Wayne: Ok! I'm sorry about earlier. Everything is just starting to get to me. Alright babe.

Whitley and D'Wayne discuss their upcoming move to Japan for D'Wayne to take a job with Kinishewa making $\$ 80,000$ a year

D'Wayne: This isn't about 80 grand a year; it's about going one step further.

Whitley: Just remember that Ron's idea helped you make that step D'Wayne.

Freddie (Ron's girlfriend) comes to talk to Ron about attending D'Wayne and Whitley's going away party

Freddie: Would you please stop this silliness and come with me to D'Wayne Whitley's farewell party.

Ron: Rain check baby!

Freddie: Ron, they're going to leave tomorrow.

Ron: Freddie, he's not my friend.

Freddie: Hunny, he just said that stuff to you because he was angry

home

Freddie leaves to attend the going away party, while Ron stays

D'Wayne and Whitley attend their own farewell party and say their goodbyes to everyone Whitley: 6 years and I feel like I grew up. I never knew that one place could mean so much to a person. You go outside to that cold ugly world and you have a place to come back where people say we love you and you're alright.

Whitley: D'Wayne, you taught me about love and I'll never forget any of you.

D'Wayne: Some friends couldn't make it. Some that taught me not to take life so seriously. Some people that taught me about brotherhood. People like Ron Johnson. I came to Hillman as the only child and now I'm leaving with a whole lot of brothers and sisters. A lot of fathers too. Thank you for being my family.

D'Wayne and Whitley are all packed up to leave for Japan when Ron comes rushing into the house

Ron: D'Wayne!

Whitley: I'm going to go wait in the car

Ron: Freddie told me about your toast last night. I should've been there

D'Wayne: I wish you had man. Aye listen, about this idea, I was tripping. I saw all that gold, all that money

D'Wayne: It's your idea, you deserve half that money

Ron: But you put the game together and you presented it to Kinishewa 
D'Wayne: But still, you came up with half the idea, I have to send you half the money. It's only fair

Ron: D'Wayne, put it towards little Ron's or little Rhonda's college education fund Ron: Um, I made this for the baby

Ron hands D'Wayne a baby raddle

D'Wayne: You didn't make this, you brought this man

Ron: Just tell Whitley I made it

D'Wayne: You know it would make me proud (*D'Wayne hold back tears) if you'll be the godfather of my child

Ron: I got your back

Whitley: D'Wayne!

Ron: Aye man, ya'll better jet

D'Wayne: I guess we better jet. Take care of yourself brother

Ron begins to get emotional

Ron: Take care brother

D'Wayne and Ron hug as Ron cries

Whitley: You be a good boy Ronaldus

Ron: I'll miss you Whitley

D'Wayne turns to Whitley

D'Wayne: You ready to go baby?

Whitley begins to get emotional as she and D'Wayne prepares to leave Whitley: Off to a different world

D'Wayne and Whitley leave the home as Ron watches 